1 Running head: Cuticular lipid dynamics on corn silks

2 To whom all correspondence should be sent:

3 Marna D. Yandeau-Nelson

4 Iowa State University

54138 Biorenewables Research Laboratory

$6 \quad 617$ Bissell Rd

7 Ames, IA 50011-1098

$8 \quad 515-294-1079$

9 myn@iastate.edu

10

11 Research area: Biochemistry and Metabolism

12 


\section{Dynamic product-precursor relationships underlie cuticular lipid accumulation on maize}

\section{4 silks}

\section{Author list}

17 Keting Chen ${ }^{\mathrm{a}, \mathrm{b}}$, Liza E. Alexander ${ }^{\mathrm{c}}$, Umnia Mahgoub ${ }^{\mathrm{a}}$, Yozo Okazaki ${ }^{\mathrm{d}, \mathrm{e}}$, Yasuhiro Higashi ${ }^{\mathrm{d}, \mathrm{e}}$,

18 Kouji Takano ${ }^{\mathrm{d}, \mathrm{e}}$, Derek Loneman ${ }^{\mathrm{a}}$, Tesia S. Dennison ${ }^{\mathrm{f}, \mathrm{g}}$, Miriam Lopez ${ }^{\mathrm{h}}$, Reid Claussen ${ }^{\mathrm{a}}$, Layton

19 Peddicord ${ }^{\mathrm{f}, \mathrm{g}}$, Kazuki Saito ${ }^{\mathrm{d}, \mathrm{e}}$, Nick Lauter ${ }^{\mathrm{f}, \mathrm{g}, \mathrm{h}}$, Karin S. Dorman ${ }^{\mathrm{a}, \mathrm{b}, \mathrm{i}}$, Basil J. Nikolau ${ }^{\mathrm{b}, \mathrm{c}, \mathrm{g}, \mathrm{j}}$, and Marna D. Yandeau-Nelson ${ }^{\mathrm{a}, \mathrm{b}, \mathrm{g}, \mathrm{j} *}$

$22{ }^{a}$ Department of Genetics, Development \& Cell Biology, Iowa State University, Ames, Iowa

$23{ }^{\mathrm{b}}$ Bioinformatics \& Computational Biology Graduate Program, Iowa State University, Ames,

24 Iowa

$25{ }^{\mathrm{c}}$ Roy J. Carver Department of Biochemistry, Biophysics \& Molecular Biology, Iowa State

26 University, Ames, Iowa

27 d RIKEN Center for Sustainable Resource Science, Tsurumi-ku, Yokohama, Kanagawa, Japan

$28{ }^{\mathrm{e}}$ Graduate School of Bioresources, Mie University, Kurimamachiya-cho, Tsu, Mie 514-8507,

29 Japan

$30 \quad{ }^{\mathrm{f}}$ Department of Plant Pathology \& Microbiology, Iowa State University, Ames, Iowa

$31 \mathrm{~g}$ Interdepartmental Genetics \& Genomics Graduate Program, Iowa State University, Ames, Iowa

$32{ }^{\mathrm{h}}$ Corn Insects and Crop Genetics Research Unit, USDA-ARS, Ames, Iowa

33 i Department of Statistics, Iowa State University, Ames, Iowa

$34{ }^{\mathrm{j}}$ Center for Metabolic Biology, Iowa State University, Ames, Iowa

ORCID IDs: 0000-0002-5242-7239 (K.C.), 0000-0002-5244-8259 (L.E.A.), 0000-0002-4310- 
45 The product-precursor ratios in the cuticular hydrocarbon-producing pathway are impacted by

46 fatty acid precursor chain length, plant genotype and the spatio-temporal dynamic gradients of

47 maize silks.

\section{Footnotes:}

50 N.L., B.J.N. and M.D.Y.-N. conceived the research; K.C., N.L., K.D. and M.D.Y.-N. designed

51 the experiments; K.S., N.L., K.D., B.J.N., and M.D.Y. N. supervised the experiments; L.E.A.,

52 U.M., Y.O., Y.H., K.T., D.L., T.S.D., M.L., R.C., L.P., N.L., and M.D.Y.-N. performed the

53 experiments; K.C., L.E.A., U.M., K.D. and M.D.Y.-N. analyzed the data; K.C., N.L., K.D.,

54 B.J.N. and M.D.Y.-N. wrote the article with important edits and feedback from all authors.

\section{Corresponding author:}

Marna D. Yandeau-Nelson. Department of Genetics, Development and Cell Biology, Iowa State

University, Ames, IA, 50011, USA. Email: $\underline{\text { myn@iastate.edu }}$

Funding Information: This work has been supported in part by National Science Foundation award IOS-1354799 to N.L., B.J.N., and M.D.Y.-N., the State of Iowa (Iowa Agriculture and Home Economics Research Station Project IOW03649) through Iowa State University's Center for Metabolic Biology, the United States Department of Agriculture (USDA) National Institute of Food and Agriculture (NIFA) Hatch project IOW03617 and by USDA-ARS project \#5030 21000-067-00D. The content of this paper is however solely the responsibility of the authors and does not represent the official views of the NSF, NIFA or USDA.

\section{Present Addresses:}

Liza E. Alexander, Kemin Industries Inc, Des Moines, Iowa. Email: 1iz.alex@,gmail.com

Umnia Mahgoub, Rollins School of Public Health, Emory University, Atlanta, GA.

71 Email:umnia@hotmail.com

72

Reid Claussen, Novozymes, Blair, Nebraska. Email: reid.claussen@gmail.com 
Layton Peddicord, Predictive Agriculture, Corteva Agriscience, Johnston, Iowa. Email: layton.peddicord@.corteva.com

Derek Loneman, School of Medicine, Case Western Reserve University, Cleveland, Ohio.Email: dmloneman@gmail.com

Tesia Dennison, AgReliant Genetics, Sioux Falls, South Dakota. Email:

ABSTRACT

The hydrophobic cuticle is the first line of defense between aerial portions of a plant and the external environment. On maize silks, the cuticular cutin matrix is infused with cuticular lipids, consisting of a homologous series of very-long-chain fatty acids (VLCFAs), aldehydes, and hydrocarbons that serve as precursors, intermediates, and end-products of the elongation, reduction, and decarbonylation reactions of the hydrocarbon-producing pathway. To deconvolute the potentially confounding impacts of the silk microenvironment and silk development on the hydrocarbon-producing pathway, spatio-temporal cuticular lipid profiling was conducted on the agronomically important inbreds B73 and Mo17, and their reciprocal hybrids. Statistical interrogation via multivariate analyses of the metabolite abundances of the hydrocarbonproducing pathway demonstrate that the cellular VLCFA pool is positively correlated with the cuticular lipid metabolome, and this metabolome is primarily affected by the silk microenvironment and the plant genotype. Moreover, genotype has a major effect on the pathway, with increased cuticular hydrocarbon and concomitant reduction of cuticular VLCFA accumulation on B73 silks, suggesting that conversion of VLCFAs to hydrocarbons is more effective in B73 than Mo17. Statistical modeling of the ratios between cuticular hydrocarbons and cuticular VLCFAs reveals the complexity of the product-precursor ratio relationship,

101 demonstrating a significant role of precursor chain length. Longer-chain VLCFAs are preferentially utilized as precursors for hydrocarbon biosynthesis. Collectively, these findings demonstrate maize silks as an effective and novel system for dissection of the complex dynamics of cuticular lipid accumulation in plants.

105

\section{INTRODUCTION}

The cuticle is the external hydrophobic barrier covering the epidermis of most aerial terrestrial plant organs, an exception being the bark of trees (Riederer and Schreiber, 2001). The cuticle limits transpirational water loss (Yeats and Rose, 2013) and thus has a role in protecting

111 the organism from such abiotic stresses as drought, salinity, and temperature. Moreover, 
112 additional protective roles have been suggested, including protection from ultraviolet radiation

113 (Krauss et al., 1997; Shepherd and Wynne Griffiths, 2006), and from biotic stresses, such as

114 fungal and bacterial pathogens and herbivory by insects (Eigenbrode and Espelie, 1995; Serrano

115 et al., 2014). In general, these extracellular cuticular lipids can include alkyl derivatives such as

116 hydrocarbons, aldehydes, primary and secondary alcohols, ketones, and wax esters, which are

117 metabolically derived from very long chain fatty acids (VLCFAs). Additional components

118 include triterpene derivatives, such as beta-sitosterol, stigmasterol, lupeol and alpha- and beta-

119 amyrins (Jetter et al., 2006). The specific composition of the cuticular lipid metabolome is

120 dependent on the organism, tissue or organ, and temporal stage of tissue and organ development

121 (Shepherd and Wynne Griffiths, 2006; Samuels et al., 2008). For example, in maize, the cuticular

122 lipids on juvenile and adult leaves are primarily composed of alcohols, aldehydes and esters,

123 with only about $1 \%$ and $17 \%$ being hydrocarbons, respectively (Bianchi et al., 1984; Bianchi et

124 al., 1985). In contrast, for maize silks, which are the stigmatic floral tissues that receive pollen

125 and facilitate fertilization of the ovule, cuticular lipids are particularly rich in hydrocarbons,

126 comprising 40-90\% of these lipids, with only minor amounts of VLCFAs, aldehydes and

127 alcohols (Yang et al., 1992; Perera et al., 2010; Loneman et al., 2017; Dennison et al., 2019).

128 The favored model for hydrocarbon production in plants is via the reduction of a saturated or

129 unsaturated VLCFA-CoA to an aldehyde intermediate, which appears to subsequently undergo

130 decarbonylation to produce either a saturated (alkane) or unsaturated (alkene) hydrocarbon

131 (Cheesbrough and Kolattukudy, 1984; Bernard et al., 2012; Jetter et al., 2018). Because the

132 majority of VLCFAs are comprised of an even number of carbon atoms (2n, where $n$ represents

133 the number of 2-carbon units used to assemble the VLCFA), this process generates products with

134 an odd-numbered carbon chain length (i.e., $2 n-1)$. However, if the process begins with odd- 
135 numbered VLCFAs (i.e., $2 n+1$ carbons), then even-numbered hydrocarbon products are

136 produced (i.e., $(2 n+1)-1=2 n)$. Such even-numbered hydrocarbons occur in many cuticles,

137 including that of maize silks (Yang et al., 1992; Loneman et al., 2017; Dennison et al., 2019).

138 This sequence of hydrocarbon-forming reactions can occur in parallel at each VLCFA-CoA

139 chain length (i.e., at every value of $n$ ), thereby generating a homologous series of cuticular

140 hydrocarbon products with alkyl chain lengths ranging from 19-33 carbon atoms. Importantly,

141 the predicted VLCFA precursors, the aldehyde intermediates and the hydrocarbon products of

142 this decarbonylation pathway are all present in the extractable silk cuticle (Loneman et al., 2017),

143 permitting the assessment of relationships between these substrates, intermediates, and products.

144 Indeed, based on the assessment of VLCFAs, aldehydes, alkanes, and alkenes collected from

145 maize silks, a pathway model involving a series of parallel reactions has been proposed for the

146 biosynthesis of both alkanes and alkenes (Perera et al., 2010).

147 As with all biological processes, this decarbonylative hydrocarbon biosynthesis pathway is

148 genetically programmed and is regulated by many factors that integrate environmental and

149 developmental cues. Indeed, both genetic and environmental factors impact the cuticular lipid

150 metabolome on maize silks. For example, multiple characterizations of the maize silk cuticular

151 lipid metabolome revealed substantial differences (i.e., up to 10-fold) in lipid abundance among

152 various panels of inbred genotypes, demonstrating the breadth of natural variation in cuticular

153 composition (Miller et al., 2003; Perera et al., 2010; Loneman et al., 2017; Dennison et al., 2019).

154 Moreover, within any individual maize inbred line, cuticular lipid accumulation varies along the

155 length of the silks. Specifically, cuticular hydrocarbons accumulate at up to five-fold higher

156 levels on the portions of silks that have emerged from the protective husk leaves, as compared to

157 the portions that are still encased by these husk leaves (Miller et al., 2003; Perera et al., 2010; 
158 Loneman et al., 2017; Dennison et al., 2019), demonstrating an impact of silk microenvironment

159 on hydrocarbon biosynthesis. Thus, it is precisely the dynamic character of these natural systems

160 that permits the statistical interrogation of the hydrocarbon-producing network among maize

161 inbreds.

162 Herein, the hydrocarbon-producing network is characterized via cuticular lipid metabolome

163 profiling of silks along a spatio-temporal gradient from two agronomically important inbred lines,

164 B73 and Mo17, as well as their reciprocal hybrids. Supervised and unsupervised multivariate

165 analyses of the cuticular lipid profiles along the silk length reveal that both microenvironment

166 and genotype of the silks, but not silk development, greatly impact cuticular lipid compositional

167 dynamics, particularly the relationships between hydrocarbon-products and VLCFA-precursors.

168 Significantly, the product-precursor ratio varies according to the precursor carbon chain length,

169 deepening our understanding of the factors impacting the reduction-decarbonylation pathway of

170 hydrocarbon synthesis.

171

\section{RESULTS}

173 To model the metabolic network for hydrocarbon production and deconvolute the potential

174 impacts of development, microenvironment, and genetics on the dynamics of the cuticular lipid

175 metabolome, we profiled extracellular cuticular lipids along the lengths of silks collected at 3-

176 days post silk-emergence. These silks were deeply sampled ( 20 biological replicates) from four

177 maize genotypes (inbred lines B73 and Mo17, and their reciprocal hybrids, B73×Mo17 and

178 Mo17×B73) in the summer growing seasons of 2014 and 2015. The collected silks were

179 dissected into five contiguous segments, named sections A-E, from base to tip (Figure 1A).

180 These sections reflect the spatio-temporal gradient of the silk, and include the microenvironment 
181 transition of the silks, as sections A-C were husk-encased, and sections D and E were emerged

182 into the external environment (McNinch et al., 2020). All aforementioned factors are analyzed

183 with the 2014 data set, and the addition of the 2015 data allowed for the analysis of

184 environmental effects. All cuticular lipid accumulation data is available in Supplemental Table

$185 \mathrm{~S} 1$.

186

Dynamic changes in the cuticular lipid metabolome along the silk length in different

genotypes

Depending on genotype and silk section, hydrocarbons account for 85-97\%, and VLCFAs

account for $2-15 \%$ of total extractable cuticular lipids; whereas aldehydes and alcohols are

191 detected only in trace amounts $(<1 \%)$ (Figure 1, A and B; Supplemental Table S1). Irrespective

192 of the genotype, total cuticular lipid load increases acropetally (section A to E; Figure 1). A

193 three-fold increase in total cuticular lipid abundance is observed along this spatio-temporal

194 gradient for inbred line B73, whereas total abundance only doubles for inbred line Mo17, and the

195 two reciprocal hybrids (Figure 1A). Furthermore, accumulation of these lipids is non-linear, and

196 changes most abruptly at the transition between encased and emerged silks (i.e., section C to D)

197 and along the emerged portions of silks (i.e., section D to E) (Figure 1A). Indeed, regression of

198 the cuticular lipid accumulation along the silk length reveals that a quadratic polynomial model

199 (adjusted $\mathrm{R}^{2}$ ranging from 0.2 to 0.9 ) is a better fit to the dynamics of total lipids, hydrocarbons,

200 VLCFAs, and aldehydes as compared to a linear model (Supplemental Table S2).

201 The compositional dynamics of these chemical classes vary not only along the silk length,

202 but also among the different genotypes. Silks from inbred B73 and hybrid B73×Mo17

203 exhibited a decrease in the relative abundance of VLCFAs and a concomitant increase in relative 
204 abundance of hydrocarbons along the silk length (Figure 1B). In contrast, there was no change in

205 Mo17×B73 and no consistent change for Mo17 in relative abundance of VLCFAs along the silk

206 (Figure 1B), but for each silk section, cuticular VLCFA concentration for Mo17 and both

207 reciprocal hybrids was 1.7- to 4.7-fold higher than B73. The largest difference among the

208 genotypes occurs for emerged silks (sections D and E) (Figure 1A), suggesting that VLCFAs in

209 Mo17 are preferentially transported to the silk surface instead of being utilized for hydrocarbon 210 production.

211 Hydrocarbon composition, specifically the degree of unsaturation, also varies among these

212 genotypes. Although alkenes consistently comprise $\sim 50 \%$ of the hydrocarbons along the spatio-

213 temporal gradient of the silks for Mo17 and the reciprocal hybrids, for B73 the relative

214 abundance of alkenes increased from approximately $40 \%$ at the base to $50 \%$ of the hydrocarbons

215 at the tips of the silks (Figure 1B). Most alkenes harbor a single double bond (i.e. a monoene),

216 which is positioned either at the $7^{\text {th }}$ or $9^{\text {th }}$ carbon-position, irrespective of the alkyl chain-length

217 (Figure 1B). However, additional minor monoenes were identified with double bonds positioned

218 at the $14^{\text {th }}$ or $15^{\text {th }}$ carbon-positions, within hydrocarbons of 29,31 , and 33 carbon atom chain

219 lengths. Accumulation patterns of the 7- and 9-monoenes differed between the inbred lines

220 (Figure 1B). Specifically, for B73, 7-monoenes consistently comprise $\sim 50 \%$ of all alkenes along

221 the spatio-temporal gradient, while the relative abundance of 9-monoenes increased from 33\% to

$22242 \%$ (Figure 1B) of the alkenes along this gradient. In contrast, on Mo17 silks, the relative

223 abundance of both the 7- and 9-monoenes did not change along the spatio-temporal gradient, and

224 they accounted for $64 \%$ and $20 \%$ of all alkenes, respectively (Figure 1B). Thus, although the

225 absolute amounts ( $\mu \mathrm{mol} / \mathrm{g}$ dry weight tissue) of these alkenes increased by $\sim 2.5$-fold in the 
spatio-temporal gradient of the silks (Supplemental Figure S1), the relative proportions of 7- and

9-monenes remained constant for Mo17, with the 9-monoenes being less abundant (Figure 1B). microenvironment) on the dynamics of the cuticular lipid metabolome were visualized via

231 distribution of silk samples along PC1, which accounts for $31 \%$ of the total variance, is tightly

232 associated with the position along the length of silks, and mainly separates the husk-encased

233 (sections A-C) from the emerged (sections D and E) portions of the silks. Moreover, PC1 also

234 separates based upon silk development, separating section C from sections A and B within the

235 husk-encased silks of the inbred B73 and the two hybrids, as well as separating sections D and E

236 of the emerged silks from all evaluated genotypes. PC2 accounts for $19 \%$ of the total variance

237 and primarily separates genotypes, with inbred lines B73 and Mo17 forming subclusters, and the

238 hybrids forming a third cluster, which is closer to Mo17 than B73.

239 Hence, we hypothesize that the spatio-temporal gradient of the silk has a greater influence on

240 cuticular lipid concentrations than the genetic variation that was evaluated in this study. Two-

241 way ANOVA on specific lipid classes (i.e. hydrocarbon, aldehyde and alcohol) and each

242 individual metabolite (Supplemental Table S3; Supplemental Table S4) supports this hypothesis

243 and reveals that the position along the length of the silk is the major determinant of the observed

244 variance in total cuticular lipid accumulation (accounting for $70 \%$ of the variance). The effect of

245 genotype and the two-way interaction between genotype and silk section explain a much smaller

246 proportion (between 5\% and 10\%) of the variance in the accumulation of these components

247 (Supplemental Table S4). In stark contrast, but in agreement with the major patterns in Figure 1B,

248 the majority of the observed variance in cuticular VLCFA accumulation is explained primarily 
by genotype (66\%), whereas the position along the length of the silk explains only $17 \%$ of this

250 variation.

\section{Silk microenvironment is the major driver of changes in cuticular lipid accumulation}

The variation in the cuticular lipid metabolome along the silk length may be explained by

253 either or both the silk developmental gradient and/or the change in the microenvironment of the

254 silks associated with husk-encasement status. At the time of silk collection, cell division has

255 ceased, and the developmental gradient is primarily determined by cellular elongation, which is

256 occurring only in the husk-encased portions of the silk, with an acropetal decrease in the rate of

257 cell elongation (Fuad-Hassan et al., 2008). The potentially confounding determinants of silk

258 cellular development and silk encasement status were untangled by the application of a nested

259 ANOVA statistical test. Silk encasement status explains $57 \%$ of the variation in total cuticular

260 lipid abundance, whereas the silk acropetal gradient (i.e., sections A versus $\mathrm{B}$ versus $\mathrm{C}$ for

261 encased portions, and section D versus E for emerged portions) explained only $13 \%$ of the

262 observed variance (Supplemental Table S4). One can conclude therefore, that cuticular lipid

263 accumulation is primarily impacted by the change in silk microenvironment associated with

264 emergence of the silks from the protective husk leaves.

\section{Correlations among cuticular lipid metabolites along the silk length reveal genotype-}

\section{6 dependent clustering patterns}

267 Pairwise Spearman correlation matrices between each lipid metabolite pair along the length

268 of silks were subjected to weighted gene correlation network analysis (WGCNA) (Horvath and

269 Langfelder, 2011). WGCNA is a method that was first developed for identifying clusters of co-

270 expressed genes, but is also now widely applied to metabolomics data (Shen et al., 2013; Bartzis

271 et al., 2017; Rosato et al., 2018). The cluster membership of many metabolites differs among the 
272 four genotypes that were evaluated (Figure 2; Supplemental Figure S2). In the inbred B73, and

273 the reciprocal hybrids, the majority of metabolites group into a single cluster (Table 1; Figure 2A;

274 Supplemental Figure S2) that includes hydrocarbon products $\left(H C_{2 n-1}\right.$ and $\left.H C_{2 n}\right)$ and

275 corresponding precursor VLCFAs $\left(F A_{2 n}\right.$ and $\left.F A_{2 n+1}\right)$. In contrast, in the inbred Mo17,

276 hydrocarbons and VLCFAs mostly reside in separate clusters (Table 1; Figure 2, B and C).

277 These observed differences in correlation network topologies suggest that the dynamics of

278 cuticular lipid accumulation differ between Mo17 and B73, especially the dynamics of VLCFA

279 accumulation.

280 This conclusion is confirmed by comparison of the Frobenius norms of the Spearman

281 correlation matrices, which are aggregate measures of the level of correlation among all

282 metabolite pairs as they are modulated by the spatio-temporal silk gradient of a given genotype.

283 The Frobenius norms for silks of B73 and the reciprocal hybrids were statistically higher than for

284 silks of Mo17 (Table 1), demonstrating that there are stronger correlations among the profiled

285 metabolites in each of the former genotypes as compared to Mo17.

286 A commonality among all genotypes, however, is the lack of correlation of 16- and 18-

287 carbon FAs with the majority of the cuticular lipid metabolites. Notably, these FAs are found

288 either as singleton, unclustered metabolites (B73, Mo17, Mo17×B73) or within a single small

289 cluster $($ B73 $\times$ Mo17) (Figure 2, D and E; Supplemental Figure S2), suggesting that the

290 metabolism of these fatty acids is distinct from the other cuticular lipid metabolites, i.e.

291 hydrocarbons and VLCFAs with $\geq 21$ carbons.

292 Identification of the signature metabolites that are primary contributors to compositional

293 variation in the cuticular lipid metabolome 
295 Least Squares-Discriminant Analysis (PLS-DA). This statistical strategy is commonly applied to

296 metabolite data for classification analysis and biomarker selection (Worley and Powers, 2012;

297 Bartel et al., 2013), and identified the signature metabolites that most contribute to the variation

298 in the cuticular lipid metabolome as modulated by the change in the silk microenvironment or by

299 the silk genotype. In this study, two supervised PLS-DA regression models were constructed,

300 with the explanatory variables $\left(\mathrm{R}^{2} \mathrm{X}\right)$ being the concentrations of individual cuticular lipid

301 metabolites and the response variable $\left(R^{2} Y\right)$ being either genotype (Supplemental Figure S3, A

302 and C) or silk section (Supplemental Figure S3, B and D). The corresponding weight plots,

303 illustrating the contributions of each metabolite in discriminating among genotypes or silk

304 sections, are presented in Supplemental Figure S3, C and D, respectively. The metabolites that

305 contribute the most to PLS-DA classification were identified via a variable-importance-in-

306 projection score (VIP>1; Supplemental Table S5), which is a cumulative measure of the

307 contribution of a given explanatory variable (i.e., metabolite) to a PLS-DA model (Pérez-Enciso

308 and Tenenhaus, 2003).

309 The PLS-DA classification of metabolome compositions relative to genotype yields two

310 clusters of silk samples for each of the inbred lines, and a third cluster containing the samples

311 from the two hybrids (Supplemental Figure S3A). The resulting model explained 63\% and 66\%

312 of the variance in the explanatory $\left(\mathrm{R}^{2} \mathrm{X}\right)$ and response $\left(\mathrm{R}^{2} \mathrm{Y}\right)$ variables, respectively. The

313 predictive accuracy is relatively low for this model (i.e., $\mathrm{Q}^{2} \mathrm{Y}=63 \%$ ), due to the inability to

314 correctly classify the metabolite compositions between the two hybrids, B73 $\times$ Mo17 and

315 Mo17×B73, which express similar cuticular lipid metabolomes. However, upon combining the

316 metabolite data from the two hybrids into a single group, the predictive accuracy of the model 
317 was improved $\left(\mathrm{Q}^{2} \mathrm{Y}=88 \%\right)$. As visualized in the PLS-DA scatter plot, the signature lipids (i.e.,

318 VIP scores $>1$ ) identified in the original PLS-DA model are major contributors to sample

319 classification, primarily differentiating B73 from Mo17, and these two parental lines from the

320 B73 $\times$ Mo17 and Mo17×B73 hybrids (Supplemental Figure S3A; black circles). These signature

321 metabolites (10 fatty acids and 5 hydrocarbons) (Figure 3, A and C) are one third of the total

322 number of detected cuticular lipid metabolites but account for two thirds of the observed

323 variance in the response variable.

324 The PLS-DA classification model of metabolome compositions relative to the spatio-

325 temporal silk gradient yields one cluster that is specific to husk-encased sections A and B, and

326 three individual clusters specific to silk sections $C, D$, and $E\left(R^{2} X=55 \%, R^{2} Y=31 \%, Q^{2} Y=28 \%\right.$;

327 Supplemental Figure S3B). A PLS-DA model that distinguishes silk sections based on husk-

328 encasement status improves the predictive accuracy $\left(\mathrm{Q}^{2} \mathrm{Y}\right)$ from $28 \%$ to $79 \%$, demonstrating the

329 importance of the silk microenvironment in shaping the cuticular lipid metabolome. Moreover,

330 the PLS-DA model that classifies the metabolomes by silk sections, identified 21 signature

331 metabolites (8 fatty acids, 2 aldehydes and 11 hydrocarbons) (Supplemental Figure S3D, black

332 circles), each of which exhibited statistically significant differences in patterns of accumulation

333 among the silk sections (Figure 3, B and C). In combination, these signature metabolites account

334 for $75 \%$ of the variance observed for silk sections. Notably, six metabolites (four saturated fatty

335 acids, an unsaturated fatty acid, and an alkane) were selected as signature metabolites that

336 contribute to the variation observed across both different genotypes and different silk sections

337 (Figure 3B). Collectively, these quantitative statistical analyses demonstrate the importance of

338 both the silk microenvironment and the silk genotype on determining the cuticular lipid

339 composition, and further identify that the accumulation of many of the VLCFA precursors, 
340 aldehyde intermediates and hydrocarbon products are differentially influenced by these two

341 factors.

342 Cellular free VLCFAs and cuticular VLCFAs are positively correlated

343 The VLCFAs that contribute to the assembly of the silk cuticle are products of the

344 endoplasmic reticulum-associated fatty acid elongase, and these VLCFAs can also be utilized to

345 assemble other cellular complex lipids (e.g., phospholipids, neutral lipids and ceramide lipids).

346 Therefore, we sought to explore the relationship between cellular VLCFAs and those associated

347 with cuticular lipids. Hence, in parallel to the preparation of cuticular lipid extracts from silks of

348 B73 and Mo17 inbreds (Figure 4A), total cellular lipids were extracted and analyzed from these

349 silks (Figure 4, B and C). The cellular lipids were profiled by liquid chromatography-mass

350 spectrometry (LC-MS), which identified the occurrence of free VLCFAs and VLCFAs that were

351 associated with complex lipids. The cellular complex lipid VLCFAs were associated with three

352 ceramides, containing $\mathrm{FA}_{22: 0}, \mathrm{FA}_{24: 0}$, or $\mathrm{FA}_{26: 0}$, one phosphatidylcholine molecular species that

353 contained $\mathrm{FA}_{20: 0}$ and one triacylglycerol molecular species that contained $\mathrm{FA}_{22: 0}$. The free

354 VLCFAs included eight saturated VLCFAs of 20- to 34-carbon chain lengths (Supplemental

355 Table S6).

356 Of the three VLCFA pools that were evaluated (i.e., cellular free VLCFAs, lipid-associated

357 VLCFAs, and cuticular VLCFAs), the cellular free VLCFA fraction increased in abundance

358 from the base to the tip of the silks (Figure 4). This increase in cellular free VLCFAs correlated

359 with the cuticular VLCFA fraction on silks of both B73 (Pearson correlation coefficients, 0.65 to

360 0.92) and Mo17 (0.87 to 0.94), whereas no such correlation was observed with the cellular lipid-

361 associated VLCFAs for either genotype (Supplemental Table S7). These results are consistent 
362 with the model that the cellular free VLCFA pool contributes to the accumulation of VLCFAs in

363 the silk cuticle.

364 Cuticular lipid product-precursor ratios vary among genotypes and across acyl chain

365 lengths

366 The dynamics of the hydrocarbon-producing pathway were explored by comparing the

367 steady state abundances of cuticular hydrocarbon products and the corresponding VLCFA

368 precursors that accumulate on the silk surface. The signature cuticular lipids that distinguish

369 either or both genotypes and silk sections include six pairs of saturated or unsaturated

370 hydrocarbons and fatty acids (i.e., either $H C_{(2 n-1): 0}$ and $F A_{2 n: 0,}$ or $H C_{(2 n-1): 1}$ and $F A_{2 n: 1}$ metabolites)

371 (Supplemental Figure S4). These can be considered "product-precursor" pairs of parallel

372 hydrocarbon producing pathways (Perera et al., 2010). There is a striking difference in the

373 accumulation of these VLCFAs as compared to the hydrocarbons along the silk spatio-temporal

374 gradient in the two inbreds. Namely, as compared to B73 silks, at the more prevalent carbon

375 chain lengths, VLCFAs are 2- to 13-fold more abundant in Mo17, whereas hydrocarbons are 2-

376 to 13-fold less abundant in Mo17 (Supplemental Figure S4). These distinct accumulation

377 patterns of hydrocarbons and VLCFAs between the two inbreds suggest that the conversion of

378 each VLCFA to the corresponding hydrocarbon may not proceed to the same extent in Mo17

379 silks, as compared to B73 silks.

380 Further interrogation of the product-precursor ratios revealed that precursor chain length was

381 the most influential factor on these ratios. In the four genotypes examined, the saturated VLCFA

$382\left(F A_{2 n: 0}\right)$ of each product-precursor pair decreased in abundance with increasing carbon chain

383 length, concomitant with an increase in the corresponding alkane product $\left(H C_{2 n-1: 0}\right)$ (Figure 5;

384 Supplemental Figure S5). Indeed, regression analysis of the product-precursor ratio (i.e., $H C_{2 n-1: 0}$ : 
$\left.F A_{2 n: 0}\right)$ confirms a linear increase in the value of this ratio as the carbon chain length increases

386 from 22 to 28 ( $\mathrm{p}$-values $<0.0001, \mathrm{R}^{2} \geq 0.79$; Figure 5; Supplemental Figure $\mathrm{S} 5$ ), and this is

387 independent of silk husk-encasement status or genotype. This statistically significant linear

388 relationship suggests that with increasing acyl chain length, silk VLCFAs are increasingly

389 recruited as precursors for the biosynthesis of hydrocarbon products.

390 Based on the observations that this product-precursor ratio increases with increasing chain

391 length (Figure 5) and that cuticular VLCFAs of longer chain lengths are less abundant on the silk

392 surface (Supplemental Table S1), Bayesian model selection was used to interrogate the other

393 factors that may affect this ratio. Specifically, while keeping metabolite chain length $(2 n)$ in the

394 baseline model, our goal is to establish the relative importance of the other variables (i.e.,

395 genotype, husk-encasement status, growing year, cellular free VLCFAs, and lipid-associated

396 VLCFAs on the product-precursor ratio). The construction of Bayesian regression models and

397 the methods of their comparisons are detailed in Supplementary Methods. Because we did not

398 have a single dataset that integrates the factors of both cellular VLCFAs and growing year, we

399 performed two Bayesian Model Comparisons, examining the impact of cellular VLCFAs on the

400 product-precursor ratio (i.e., VLCFA model selection) or the impact of growing year on this ratio

401 (i.e., Environment model selection).

402 To assess the impact of cellular VLCFAs on product-precursor ratios, we considered three

403 Bayesian regression models: VLCFA model 1, which includes cellular free-VLCFAs; VLCFA

404 model 2, which includes cellular lipid-associated VLCFAs; and VLCFA model 3, which includes

405 both cellular free and lipid-associated VLCFAs (Table 2). The predictor variables included in

406 each VLCFA model were selected by preliminary Bayesian Model Comparison (see

407 Supplemental Methods; Supplemental Table S8) from the variables genotype, husk-encasement 
status, and metabolite chain length, as well as those associated with two-way and three-way interaction terms among these predictor variables. Subsequently, a second round of Bayesian

410 Model Comparison was performed to compare a model without VLCFA variables (Baseline

411 Model) to VLCFA models 1, 2, and 3. The resultant Bayes factors demonstrate a substantial

412 increase in the ability of each of the VLCFA models to explain patterns of product-precursor

413 relationships when incorporating cellular VLCFAs, be they free or lipid-associated VLCFAs

414 (Table 2). However, the incorporation of free VLCFAs in the model (i.e., VLCFA model 1)

415 results in the highest Bayes factor $\left(1.88 \times 10^{7}\right)$, demonstrating that the cellular free VLCFAs have

416 the highest influence on the product-precursor ratios of the cuticular lipids. Furthermore, the high

417 correlation between the cellular free VLCFAs and the cuticular VLCFA pool (Supplementary

418 Table S7) is consistent with the precursor role of very long chain fatty acyl-CoAs as the

419 precursors for cuticular hydrocarbon biosynthesis.

420 Subsequently, using combined data collected from the two growing years, we queried the

421 effect of growing year on product-precursor relationships in the context of the different

422 genotypes and silk encasement status (Table 3, Environment model selection). Because the

423 cellular VLCFA pools were not measured in the first growing year, free VLCFAs, lipid-

424 associated VLCFAs and the related interaction terms were not included in this modeling effort.

425 The genotype factor exhibited the strongest impact on this product-precursor relationship in the

426 combined dataset (Bayes factor $=1.01 \times 10^{110}$, Table 3, Environment model selection). Growing

427 year $\left(\right.$ Bayes factor $\left.=2.35 \times 10^{33}\right)$ and husk-encasement status $\left(\right.$ Bayes factor $\left.=7.76 \times 10^{28}\right)$ also

428 impacted the product-precursor ratios, although to a lesser extent. Similarly, such quantitative

429 modeling analyses indicate that the two-way interactions between genotype and husk encasement

430 status, and between genotype and growing year also play a role in determining the product- 
431 precursor ratio dynamics along the silk spatio-temporal gradient (Supplemental Table S2), but

432 husk encasement status and year does not. Collectively therefore, these analyses illustrate the

433 complexity of factors that influence product-precursor relationships with respect to alkyl carbon

434 chain length of cuticular lipid components.

\section{DISCUSSION}

In this study we utilized cuticular lipid profiling data gathered from the spatio-temporal gradient of maize silks to assess and compare the dynamics of the metabolic network that

439 supports cuticular hydrocarbon accumulation. Previously, a series of parallel pathways has been

440 proposed for the biosynthesis of these hydrocarbons, which are primarily composed of alkanes

441 and alkenes (Perera et al., 2010). These pathways involve elongation of fatty acids, followed by

442 reduction and decarbonylation to generate a homologous series of alkanes. In parallel, a

443 homologous series of alkenes can be generated from the reduction and decarbonylation of

444 unsaturated fatty acids that either undergo desaturation followed by elongation, or elongation

445 followed by desaturation.

446 We investigated the cuticular lipid metabolomes for the maize B73 and Mo17 inbred lines,

447 and the corresponding reciprocal hybrids. Genotypic variation of cuticular lipid compositions

448 occurs primarily between the two inbred parents (i.e., B73 versus Mo17) and between the inbred

449 parents and the hybrids, but not between the reciprocal hybrids, B73 $\times$ Mo17 and Mo17×B73.

450 While some plant molecular phenotypes (e.g., chloroplast thylakoid lipid composition and

451 localization; Dueñas et al., 2017) and gene expression profiles (Gonzalo et al., 2007; Swanson-

452 Wagner et al., 2009) can differentiate these reciprocal hybrids, such observations are less

453 common than the differences that occur between the parental inbred lines (Paschold et al., 2012; 
454 Baldauf et al., 2016; Marcon et al., 2017). The remainder of the discussion is therefore focused

455 on the cuticular lipid metabolomes and the apparent variation in the underlying hydrocarbon-

456 producing pathway between the two inbred parents.

Maize silks as a novel system to study the dynamics of the cuticular lipid biosynthesis

pathway

Maize silks provide a unique platform for assessing the dynamics of hydrocarbon production,

461 in the absence of complex flux analysis approaches. Many characterizations of the cuticular lipid

462 biosynthesis pathway have been conducted for single time-point comparisons of metabolomes

463 profiled from different genetic backgrounds (as reviewed by Xue et al., 2017 and Trivedi et al.,

464 2019). In this study, cuticular lipid profiling captures differences in accumulation of precursors,

465 intermediates, and products of the pathway along a spatio-temporal gradient that includes the

466 developmental progression of silks (Fuad-Hassan et al., 2008) as well as an environmental

467 transition as portions of the silks change encasement status from husk-encased to husk-emerged,

468 when silks become exposed to the external environment. Similar spatio-temporal studies have

469 identified metabolic shifts in primary, secondary, and lipid metabolism along the lengths of

470 leaves in Arabidopsis, tobacco, wheat and maize (Pick et al., 2011; Watanabe et al., 2013;

471 Allwood et al., 2015; Li et al., 2017; Zhou et al., 2019; Bourgault et al., 2020).

472 In the case of maize silks, the hydrocarbon end-products of cuticular lipid biosynthesis

473 accumulate extracellularly on the silk surface (Perera et al., 2010; Loneman et al., 2017),

474 whereas VLCFAs accumulate both internally as either free VLCFAs or lipid-associated VLCFAs

475 (e.g. triacylglycerols and ceramides), and on the silk surface as components of the cuticle. Here

476 we show that the concentrations of individual fatty acids that accumulate on the silk surface are 
477 highly correlated with the concentrations of corresponding free cellular VLCFAs. The exceptions

478 to this observation are the 18-carbon fatty acids (i.e. stearic and oleic acids), whose

479 concentrations are poorly correlated between the cellular lipid fraction and the cuticular lipid

480 fraction. This lack of correlation is attributable to the role of 18-carbon fatty acids as initial

481 precursors for elongation of VLCFAs (Bach and Faure, 2010), and as building blocks in the

482 assembly of numerous complex lipids, including for membrane glycerolipids (Sato and Awai,

483 2017), phospholipids (Nakamura, 2017), and sphingolipids (Michaelson et al., 2016). Indeed, an

484 appreciable amount of saturated and unsaturated 18-carbon fatty acids profiled from silk tissue

485 were associated with complex cellular lipids, such as triacylglycerol or phosphatidylcholine. In

486 contrast, VLCFAs are components of cuticular lipids, the ceramide component of sphingolipids

487 (Dietrich et al., 2005) and some discrete phospholipids (Michaelson et al., 2016), which is

488 consistent with our observation that VLCFAs are recovered from the silk cuticle and as

489 components of three specific cellular glucosylceramide species harboring a single hydroxylated

490 C22-, C24- or C26-VLCFA moiety. Collectively, these observations suggest that the spatio-

491 temporal accumulation of VLCFAs on maize silks reflects the dynamics of the steady-state

492 levels of the cellular free VLCFA precursor pool utilized by the hydrocarbon-producing pathway.

493 The silk microenvironment significantly impacts the cuticular lipid metabolome and the

494 hydrocarbon-producing pathway

495 Emergence of the silks from the encasing husk-leaves has previously been shown to induce

496 increased accumulation of cuticular hydrocarbons in different maize genotypes (Yang et al.,

497 1992; Miller et al., 2003; Perera et al., 2010; Loneman et al., 2017; Dennison et al., 2019).

498 However, in each of these prior studies that compared the cuticular lipid metabolome between

499 husk-encased and emerged portions of silks, the change in microenvironment (i.e. silk 
encasement status) was overlaid with a confounding developmental gradient, particularly that of an acropetal decrease in cellular elongation within the husk-encased silks at the time of tissue

502 sampling (Fuad-Hassan et al., 2008). This study shows that the change in microenvironment per

503 se (i.e. husk-encased vs emerged silks) drives the observed change in cuticular lipid composition,

504 as well as the product-precursor relationships within the cuticular hydrocarbon-producing

505 pathway. Indeed, a recent transcriptomic atlas for maize silks has identified microenvironment-

506 based differential gene expression for many genes involved in cuticular lipid biosynthesis, and

507 more broadly for genes involved in responses to biotic and abiotic stresses (McNinch et al.,

508 2020). Interestingly, the increase in cuticular hydrocarbon accumulation that is observed in

509 emerged silks of B73, the B73 $\times$ Mo17 and Mo17 $\times$ B73 hybrids and, to a lesser extent, Mo17, may

510 provide protection against drought, as for example, the observed increase in alkane accumulation

511 upon drought stress that occurs in soybean and sesame (Kim et al., 2007a; Kim et al., 2007b).

\section{Supervised and unsupervised multivariate analyses identified key factors that impact the}

\section{3 hydrocarbon-producing pathway}

514 In metabolomic studies, correlation networks are often used to identify metabolites that are

515 co-regulated in response to perturbations caused by disease, chemical and other environmental

516 treatments, and genetic modifications (DiLeo et al., 2011; Fukushima et al., 2011; Papazian et al.,

517 2016; Angelovici et al., 2017). Such correlation networks have been constructed from non-

518 targeted metabolomics data gathered from different maize inbred lines, which capitulate

519 pathways of primary metabolism in leaves (Toubiana et al., 2016; Zhou et al., 2019) and kernels

520 (Rao et al., 2014). However, the correlative relationships of metabolites within targeted

521 metabolomes are more complex, as queried metabolites are often from highly related pathways,

522 and therefore the accumulation patterns of most metabolites are inherently correlated. Even so, 
523 such correlation networks have successfully described a change in metabolic states due to change

524 in development-, genotype-, or stress-specific impacts (Steuer, 2006; Sawada et al., 2009; Warth

525 et al., 2015; Li et al., 2016; French et al., 2018). In our correlation analyses of metabolites

526 involved in the hydrocarbon-producing network, hydrocarbon products and corresponding

527 precursor VLCFAs separated into different clusters within the correlation network in Mo17,

528 whereas these products and precursors are highly correlated in B73.

529 The combination of metabolite profiling and subsequent statistical analysis allows for the

530 identification of signature metabolite biomarkers that represent changes in metabolic status

531 induced by genetic or environmental perturbations, or by tissue development (Fernandez et al.,

532 2016; Hong et al., 2016). For example, metabolite biomarkers have successfully uncovered

533 variations within complex pathways in response to developmental or environmental stimuli in

534 Arabidopsis (Sulpice et al., 2009), rice (Tarpley et al., 2005), maize (Obata et al., 2015; Luo et

535 al., 2019), Brassica nigra (Papazian et al., 2016) and wheat (Kang et al., 2019). Herein, we

536 identified 30 cuticular lipids as signature metabolites that include six pairs of cuticular VLCFAs

537 and hydrocarbon products. The spatio-temporal accumulation pattern of these signature

538 metabolites demonstrates that the cuticular lipid-producing network is enhanced along the spatio-

539 temporal gradient of the silks, especially during the transition of the microenvironment

540 experienced by the silk tissue caused by emergence from the encasing husks. Furthermore, a

541 comparison of the concentrations of the signature metabolites between B73 and Mo17 suggest

542 that the genetic difference of the silks is key in determining the product-precursor relationship of

543 the cuticular lipid-producing network. This statistical approach for analyzing metabolomics data

544 that combined supervised and unsupervised multivariate analyses not only provides new insights

545 into the factors that impact cuticular lipid accumulation and composition, but also permits 
546 probing the status of the individual metabolite conversions within the hydrocarbon-producing

547 pathway.

548 Factors impacting the product-precursor relationship

549 Product-precursor relationships have previously been inferred from cuticular lipid profiles of

550 several systems. These include the relationships between alkanes, secondary alcohols, and

551 ketones, and the relationships between VLCFAs, alcohols and wax esters of Arabidopsis cuticles

552 (Lai et al., 2007; Wen and Jetter, 2009), the relationships between primary and secondary diols

553 and esters of the wheat cuticle (Racovita and Jetter, 2016), and relationships between unsaturated

554 aldehydes and alkenes of the maize cuticle (Perera et al., 2010). In each case, the presence of

555 precursors that are chemically related by a potential biochemical reaction was posited to

556 demonstrate biosynthetic relationships amongst these metabolites.

557 In this study, we compared the accumulation pattern of cuticular alkanes $\left(H C_{2 n-1: 0}\right)$, and the

558 associated VLCFAs $\left(F A_{2 n: 0}\right)$ that can serve either as precursors in the pathway or can themselves

559 be deposited as cuticular lipid products. More specifically, we considered that the individual

560 VLCFAs queried in this study can serve as precursors for three processes: (1) fatty acid

561 elongation that generates longer chain VLCFAs, (2) sequential reduction-decarbonylation

562 reactions that generate alkanes, or (3) export to the silk cuticle to generate the cuticular VLCFA

563 pool. Along the spatio-temporal gradient of the silks, both cuticular and total cellular VLCFAs

564 increase in accumulation. Thus, VLCFA biosynthesis is likely promoted in the distal end of the

565 spatio-temporal gradient of silks, resulting in increased cuticular lipid load as either free

566 VLCFAs or VLCFA-derived hydrocarbons produced by a series of elongation-reduction-

567 decarbonylation reactions (Perera et al., 2010). 
A Bayesian approach has previously been employed to predict protein trafficking routes

569 (Paultre et al., 2016), to elucidate genomic and environmental controls over plant phenotypes

570 (Allard et al., 2016; Di Guardo et al., 2017; Montesinos-López et al., 2017; Wang et al., 2019),

571 and to assess gene-to-metabolome associations (Marttinen et al., 2014). In this study, Bayesian

572 model testing validated the supposition that the cellular free VLCFA levels are the most

573 impactful factors affecting product-precursor relationships. Similar relationships between

574 cuticular lipid products and their acyl precursors have been observed in both Arabidopsis and

575 leek. In Arabidopsis, the relationship between VLCFA precursors and alkane products along the

576 developmental gradient from the base to the apex of the leaf was associated with a concomitant

577 increase in KCS6 expression, a gene encoding for an enzyme required for the synthesis of

578 VLCFA precursors (Busta et al., 2017). Similarly, in leek, VLCFA elongase activity increases

579 along the spatio-temporal gradient of the leaf blade and is correlated with a $\sim 1000$-fold increase

580 in the cuticular ketones, which are the major products in this cuticle (Rhee et al., 1998).

581 Other factors that significantly impact the cuticular lipid product-precursor relationships

582 include the genetic background and the husk encasement status of the silks. Statistical

583 assessment of the product-precursor ratios suggests that cuticular hydrocarbon production is less

584 active in Mo17 as compared to B73, and that potential environmental cues differentially impact

585 the hydrocarbon-producing pathway between these two genotypes. These different modulators

586 that impact the product-precursor ratios can be mechanistically explored either by transgenic

587 strategies that will evaluate individual genes that could impact product-precursor relationships,

588 or by studying different genotypes that could evaluate the impact of different combinations of

589 alleles on product-precursor relationships. 
A key observation made in this study is that the product-precursor ratio increases with

591 increasing alkyl chain length, demonstrating a preference toward the production of longer-chain

592 hydrocarbons via parallel reduction-decarbonylation reactions. There are a number of potential

593 mechanisms that could generate this change between the product-precursor ratio and acyl chain

594 length. These include variations in the substrate preferences of 1) the VLCFA elongation system;

595 2) the reductase that converts VLCFAs to aldehydes; and 3) the decarbonylase that converts

596 aldehydes to hydrocarbons. Indeed, chain length preferences have been identified for several of

597 the 21 ketoacyl-CoA synthetases (KCSs) responsible for the condensation reaction of the fatty

598 acid elongase that generates VLCFAs of Arabidopsis (Millar and Kunst, 1997; Fiebig et al., 2000;

599 Blacklock and Jaworski, 2006; Joubès et al., 2008; Kim et al., 2013; Hegebarth et al., 2016;

600 Hegebarth et al., 2017) and similar preferences are likely to exist amongst the 26 putative KCSs

601 identified in maize (Campbell et al., 2019). Moreover, the observed substrate specificities of the

602 alkane-forming reductase-decarbonylase enzyme complexes may be associated with homologs of

603 the Arabidopsis CER1 and CER1-LIKE1 proteins, which can each form a unique reductase-

604 decarbonylase complex with CER3 homologs (Pascal et al., 2019). These hypotheses could be

605 tested via heterologous expression of candidate genes within the recently engineered yeast

606 system expressing the maize fatty acid elongase complex (Campbell et al., 2019; Pascal et al.,

607 2019).

608

609 CONCLUSIONS

610 In this study we demonstrate that the combination of spatio-temporal profiling and multivariate

611 analyses is an effective approach for assessing and comparing metabolic networks that are

612 differentially impacted by developmental and environmental perturbations among different 
613 genotypes. Compositional dynamics of this cuticular lipid metabolome were most impacted by

614 silk microenvironment and genotype, with very little impact of silk development. This study

615 establishes that product-precursor ratio dynamics for the hydrocarbon-producing pathway can be

616 inferred from cuticular lipid composition. These product-precursor relationships are complex and

617 dependent upon the composition of cellular VLCFA pools, the genetic background of the organ

618 or tissue, and most significantly, precursor chain length, such that longer chain VLCFAs are

619 preferentially utilized as precursors in hydrocarbon biosynthesis. These findings provide the

620 foundation for the dissection of the underlying mechanisms of the hydrocarbon-producing

621 pathway in response to changes in microenvironment, ultimately leading to a genotype-

622 metabolite-phenotype understanding (Yandeau-Nelson, 2015) of cuticular lipid accumulation,

623 and resultant protective capacity of cuticular lipids on plant surfaces.

625 MATERIALS AND METHODS

626 Nomenclature

627 Cuticular lipid metabolites are represented using a $n: y(z)$ notation, where $n$ represents the 628 number of carbon atoms, $y$ the number of double bonds, and $z$ the positions of the double bonds 629 in the alkyl chain (Howard and Lord, 2003). This study reports three classes of cuticular lipids;

630 very-long-chain fatty acids (VLCFAs) that are saturated $\left(F A_{n: 0}\right)$ or unsaturated $\left(F A_{n: y(z)}\right)$,

631 saturated aldehydes $\left(\operatorname{Ald}_{n: 0}\right)$, and hydrocarbons $(\mathrm{HCs})$, which include saturated alkanes $\left(H C_{n: 0}\right)$,

632 and two classes of alkenes: monoenes $\left(H C_{n: 1(z)}\right)$, and dienes $\left(H C_{n: 2(z 1, z 2)}\right)$.

633

634 Plant growth, sample collection and processing 
636 were grown to maturity at the Iowa State University Agronomy Research Farm (Boone, IA)

637 during the 2014 and 2015 growing years using standard cultivation practices and no

638 supplemental irrigation. Developing ear shoots were covered prior to silking to prevent

639 pollination. Ears were harvested three days after silks had emerged from encasing husk leaves, at

640 a point at which half of the plants in a row were silking (i.e. the mid-silk cohort). Ears were

641 harvested between $11 \mathrm{am}$ and $1 \mathrm{pm}$ each day and were transported to the laboratory at ambient

642 temperature using insulated chests. The number of biological replicates sampled per genotype

643 were 8 and 12 in the 2014 and 2015 growing years, respectively. Each biological replicate

644 consisted of silks from two ears of similar size and appearance, harvested on the same day. Silk

645 samples were prepared as described in McNinch et al. (2020). For each biosample, one sub-

646 sample was flash-frozen in liquid nitrogen and reserved for subsequent total VLCFA profiling

647 and the second sub-sample was immediately subjected to cuticular lipid extraction.

\section{Lipid extraction and derivatization}

649 Extracellular cuticular lipids were extracted from fresh silks by immersion for 4 min in 9:1

650 hexanes: diethyl ether supplemented with the internal standards eicosane $(1 \mu \mathrm{g} / \mathrm{ml})$, nonadecanoic

651 acid $(1 \mu \mathrm{g} / \mathrm{ml})$ and heptadecanol $(1 \mu \mathrm{g} / \mathrm{ml})$, as previously described (Loneman, 2017). Extracts

652 were concentrated under a stream of $\mathrm{N}_{2}$ gas in a N-EVAP nitrogen evaporator (Organomation

653 Associates, Inc., MA). Extracts were chemically derivatized via transmethylation followed by

654 silylation, as previously described (Loneman, 2017). For total lipid analyses, intra- and

655 extracellular lipids were extracted as previously described (Okazaki, 2015) from 5-8 mg of

656 lyophilized silk tissue that had been pulverized to a fine powder using a Mixer Mill 301 (Retsch

$657 \mathrm{GmbH}$, Germany). 


\section{Chromatography}

Gas chromatography of cuticular lipid extracts was performed with an HP-5MS cross-linked

660 (5\%) diphenyl (95\%) dimethyl polysiloxane column (30m in length; $0.25-\mathrm{mm}$ inner diameter)

661 using helium as the carrier gas, and an Agilent Technologies series 6890 gas chromatograph,

662 equipped with a model 5973 mass detector (Agilent Technologies, Santa Clara, CA). Extracts

663 were introduced to the gas chromatograph via splitless injection of a $2-\mu 1$ sample and the oven

664 temperature program was as listed for samples that were both transmethylated and silylated

665 (Loneman, 2017). Quantification analysis was performed using the AMDIS software package

666 (Stein, 1999) with assistance from the NIST Mass Spectral library

667 (http://webbook.nist.gov/chemistry/) for compound identification.

668 Total lipid analysis was performed on a random selection of four biological replicates from

669 the total number of replicates collected in the 2015 growing year. Total lipid extracts were

670 analyzed via liquid chromatography quadrupole time-of-flight mass spectrometry on a Waters

671 Xevo G2 Q-TOF MS combined with a Waters ACQUITY UPLC system in both positive and

672 negative ion modes, as previously described (Kimbara et al.,2013). LC-MS data were recorded

673 using MassLynx4.1 software (Waters) and processed using MarkerLynx XS software (Waters).

674 The data matrices were queried against an in-house lipid library (RIKEN, Japan). For data

675 normalization, the original peak intensity values were divided by the internal standard peak

676 intensity value at $\mathrm{m} / \mathrm{z} 566.382[\mathrm{M}+\mathrm{H}]^{+}$and $\mathrm{m} / \mathrm{z} 550.351\left[\mathrm{M}-\mathrm{CH}_{3}\right]^{-}$for the positive and negative

677 ion modes, respectively.

\section{Quantitative methods}

679 Cuticular lipid metabolite concentrations were initially calculated relative to the compatible

680 internal standard (i.e. hydrocarbons quantified relative to eicosane, VLCFAs relative to 
681 nonadecanoic acid, and alcohols and aldehydes relative to heptadecanol). Because quantification

682 of each metabolite class did not differ depending on choice of standard, all subsequent

683 quantifications were relative to the eicosane standard. Quantification was performed relative to

684 silk dry weight, to avoid potential differences in metabolite concentrations due solely to

685 differences in water content between genotypes or among silk sections. Representative

686 measurements of silk dry weight were calculated for each silk section (A-E) from surrogate ears

687 harvested on the same days as those used for cuticular lipid profiling, and a ratio of dry weight to

688 fresh weight was calculated as a conversion factor to estimate the dry weight of extracted silk

689 samples, as described by Loneman et al. (2017). The measured water content of silk samples was

690 approximately 90\% regardless of the position along the silk length, the genetic background, or

691 the growing year.

Detection limits were determined as previously described (Dennison et al., 2019). The

693 detection limits for the datasets collected in growing years 2014 and 2015 were 0.005 and 0.006

$694 \mu \mathrm{mol} \mathrm{g}{ }^{-1}$ dry weight, respectively. Metabolite abundances were censored (Newman et al., 1989)

695 such that concentrations below the detection limit (DL) were assigned a value of DL/2, and

696 concentrations for metabolites that were not detected in a specific condition were assigned the

697 value, DL/10. Consistently low abundance metabolites that were assigned DL/2 or DL/10 values

698 for more than $90 \%$ of the samples were removed from the dataset.

\section{Statistical Methods}

The raw metabolite data were log-transformed and pareto-scaled. ANOVA was performed to

701 evaluate the effects of genotype, position along the silk, growing year, and cellular free VCLFA

702 and cellular lipid-associated VLCFA content on cuticular lipid composition. For each genotype,

703 the accumulation dynamics along the silk length for each lipid class were modeled using linear 
704 and polynomial (i.e., quadratic, cubic and quartic models) regression. The regression model that

705 best fitted the concentration data for each lipid class was determined by comparing the adjusted

$706 \mathrm{R}^{2}$ of the four regression models. Tukey's HSD tests were applied for post-hoc pairwise

707 comparisons between silk sections either within or among genotypes. These analyses were

708 conducted using the $\mathrm{R} /$ stats base package ( $\mathrm{R}$ core team 2016).

709 PCA was performed using the $\operatorname{prcomp}()$ function in the $\mathrm{R} /$ stats package and $95 \%$ confidence

710 ellipses were constructed using R/car dataEllipse() function (Fox and Weisberg, 2011). Partial

711 least squares-discriminant analysis (PLS-DA) was performed using R/ropls opls() function that

712 also determined the optimal number of components for the PLS-DA model using seven-fold

713 cross validation (Thevenot et al., 2015). Variable Importance in Projection (VIP) scores were

714 calculated by $\mathrm{R} /$ ropls getVip $\operatorname{Vn}()$ function as a cumulative measure of the contribution of each

715 metabolite in distinguishing among genotypes or silk sections (Pérez-Enciso and Tenenhaus

716 2003). Individual metabolites with VIP scores $>1.0$ (i.e. with above-average contribution in

717 sample classification) were deemed as metabolite biomarkers that discriminate between classes.

718 The explained fraction of data variance by a PLS-DA model for explanatory and response

719 variables were reported as $R^{2} \mathrm{X}$ and $\mathrm{R}^{2} \mathrm{Y}$, respectively, and the predictive accuracy of the model

720 was reported as $\mathrm{Q}^{2} \mathrm{Y}$. The response variable for PLS-DA is categorical and therefore transformed

721 into a binarized numerical variable for model construction, and $\mathrm{R}^{2} \mathrm{Y}$ represents the explained

722 variation within the transformed data.

723 Non-parametric Spearman correlations between every pair of metabolites across silk sections

724 A to E were calculated in each genotype, and were compared among genotypes according to

725 Choi and Kendziorski (2009), with modifications that are described in Supplemental Methods.

726 The metabolite correlation networks were constructed based on topological overlap matrices 
727 (TOMs) derived from the correlation matrices using the R/WGCNA package (Langfelder and

728 Horvath, 2008). Briefly, for each genotype, metabolite clusters were initially determined

729 according to TOMs by hierarchical clustering and then pruned by four independent R functions:

730 pam(), cutreeStatic(), and two cutreeDynamic()s with the "methods" argument specified as either

731 “tree” or "hybrid” (Horvath and Langfelder, 2011).

732 The ratios of $H C_{2 n-1: 0}: F A_{2 n: 0}$ relative to the carbon chain length $2 n$ were fitted into a linear

733 regression model as the response variable using the $\mathrm{R} /$ stat function $\operatorname{lm}()$, with precursor chain

734 length, genotype, silk encasement status, growing year, and the corresponding interaction terms

735 as the explanatory variables. The prediction interval for regression was calculated by R/stat

736 function predict(). Bayesian Model Comparison, using the R/BayesFactor package (Morey and

737 Rouder 2015), was applied to assess the association of the product-precursor ratio with these

738 explanatory variables and two additional explanatory variables (concentration of cellular free

739 VLCFAs and concentration of lipid-associated VLCFAs). Bayesian model construction and

740 comparison are described in detail in Supplemental Methods.

\section{Supplemental Material}

742 Supplemental methods: Supplemental Statistical Methods

743 Supplemental Figure S1: Accumulation of cuticular monoenes along the spatio-temporal

744 gradient of silks.

745 Supplemental Figure S2: Correlation-based clustering of silk cuticular lipid abundance data for

746 hybrids, B73×Mo17 and Mo17×B73.

747 Supplemental Figure S3: Clustering of silk samples by partial least squares discriminant

748 analysis (PLS-DA) based on different genotypes and different silk sections. 
749 Supplemental Figure S4: The spatio-temporal accumulation patterns of hydrocarbon $\left(H C_{2 n-1: 0}\right)$

750 and VLCFA $\left(F A_{2 n: 0}\right)$ product-precursor pairs in inbreds B73 and Mo17.

751 Supplemental Figure S5: Accumulation of cuticular hydrocarbon products and corresponding

752 cuticular VLCFAs, and the regression of the product-precursor ratios on chain length for hybrids,

753 B73×Mo17 and Mo17×B73.

754 Supplemental Table S1: Spatio-temporal profiles of cuticular lipids from maize silks of B73,

755 Mo17, and the reciprocal hybrids that were collected in the 2014 and 2015 growing years.

756 Supplemental Table S2: Comparison of four polynomial regression models that depict the

757 dynamics of cuticular metabolite accumulation levels among the silk sections in the indicated

758 maize lines.

759 Supplemental Table S3: Two-way and two-way nested ANOVAs that test the main effect of

760 genotype $(\mathrm{G})$, silk section $(\mathrm{S})$ and $\mathrm{G} \times \mathrm{S}$ interaction on each cuticular lipid metabolite.

761 Supplemental Table S4: Two-way and three-way ANOVAs of total cuticular lipids and

762 individual lipid metabolite classes.

763 Supplemental Table S5: Variable importance in projection (VIP) score for each lipid in two

764 PLS-DA models built to discriminate genotypes or silk sections based on the cuticular lipid

765 metabolome compositions.

766 Supplemental Table S6: Spatio-temporal profiles of cellular VLCFAs from maize silks of B73

767 and Mo17 at 2015 growing year.

768 Supplemental Table S7: Pearson correlations between cellular fatty acids (free VLCFAs and

769 lipid-associated VLCFAs) and cuticular VLCFAs at individual acyl chain lengths. 
770 Supplemental Table S8: Identification of the optimal VLCFA Bayesian regression model that

771 incorporated cellular free VLCFAs and/or cellular lipid-associated VLCFAs as predictors.

772 ACKNOWLEDGEMENTS

773 The authors thank Drs. Ann Perera, Lucas Showman, and Zhihong Song at the Iowa State

774 University's W. M. Keck Metabolomics Research Laboratory for assistance and advice

775 regarding GC-MS analysis. We thank Pauline Aamodt, Grace Kuehne, Sarah (Weirich)

776 Hennings, and Kyle King for assistance with sample collection and processing.

777 
Table 1. Silk cuticular lipid metabolites from B73 and Mo17 exhibit different correlation patterns along the spatio-temporal silk gradient. The Frobenius norm is derived from the sum of squares for all the elements in a Spearman correlation matrix. Correlation-based clustering 781 was performed by WGCNA.

782

\begin{tabular}{llll}
\hline Genotype & Frobenius norm $^{1}$ & Number of clusters & Number of singletons \\
\hline B73 & $0.58^{\mathrm{a}}$ & 1 & 6 \\
Mo17 & $0.48^{\mathrm{b}}$ & 2 & 9 \\
B73×Mo17 & $0.55^{\mathrm{ab}}$ & 2 & 9 \\
Mo17×B73 & $0.54^{\mathrm{ab}}$ & 1 & 9 \\
\hline
\end{tabular}

$784 \quad{ }^{1}$ Values followed by different letters are statistically different ( $\left.\mathrm{p}<0.001\right)$ according to a random 785 permutation test as described by Choi and Kendziorski (2009). 
Table 2. Impacts of cellular free VLCFAs and lipid-associated VLCFAs on productprecursor ratios determined by Bayesian model comparison. The product-precursor relationship was represented by the linear regression of product-precursor ratio $\left(H C_{2 n-1}: F A_{2 n}\right)$ versus acyl chain length, $2 n$. Bayesian model comparison was performed on metabolomics data collected during the 2015 growing year with cellular free VLCFAs and cellular lipid-associated VLCFAs profiled from lipids extracted from the entire silk tissue. The notation for cuticular lipids is described in Methods.

\begin{tabular}{|c|c|c|c|}
\hline Baseline model & VLCFA models $^{\mathrm{a}}$ & Examined terms & Bayes factor $^{b}$ \\
\hline \multirow{3}{*}{$\begin{array}{l}\text { Genotype }(g)+ \\
\text { Encasement status } \\
(k)+\text { Acyl chain } \\
\text { length }(n)+(g \times k)+ \\
(k \times n)+(g \times k \times n)\end{array}$} & $\begin{array}{l}\text { VLCFA model } 1: g+k+n+(g \times \\
k)+(k \times n)+(g \times k \times n)+[\text { free } \\
\text { VLCFAs }(f f a)+(f f a \times g)+(f f a \times \\
k)+(f f a \times n)+(f f a \times k \times n)]\end{array}$ & $\begin{array}{l}\text { Cellular free } \\
\text { VLCFAs }(f f a) \text { and the } \\
\text { interaction effects } \\
\text { with } g, k \text { and } n\end{array}$ & $1.88 \times 10^{7}$ \\
\hline & $\begin{array}{l}\text { VLCFA model } 2: g+k+n+(g \times \\
k)+(k \times n)+(g \times k \times n)+[\text { lipid- } \\
\text { associated VLCFAs }(l f a)+(l f a \times \\
g)+(l f a \times n)]\end{array}$ & $\begin{array}{l}\text { Cellular lipid- } \\
\text { associated VLCFAs } \\
(l f a) \text { and the } \\
\text { interaction effects } \\
\text { with } g \text { and } n\end{array}$ & $5.31 \times 10^{6}$ \\
\hline & $\begin{array}{l}\text { VLCFA model } 3: g+k+n+(g \times \\
k)+(k \times n)+(g \times k \times n)+[f f a+ \\
(f f a \times g)+(f f a \times k)+(f f a \times n)+ \\
(f f a \times k \times n)+l f a+(l f a \times g)+ \\
(l f a \times n)]\end{array}$ & $\begin{array}{l}\text { Cellular free } \\
\text { VLCFAs }(f f a) \text { and } \\
\text { lipid-associated } \\
\text { VLCFAs }(l f a) \text {, and } \\
\text { interaction effects } \\
\text { with } g, k \text { and } n\end{array}$ & $4.57 \times 10^{6}$ \\
\hline
\end{tabular}

${ }^{a}$ For each VLCFA model, the main effect of the examined term and the associated interaction effects were added to the baseline model as justified in Supplementary Table S8.

${ }^{\mathrm{b}}$ Bayes factors were calculated as the ratio of the likelihood between VLCFA models

798 (numerator) and the baseline model (denominator). A Bayes factor $>3.2$ indicates that the

799 addition of the examined terms to the baseline model resulted in significantly better fit to the data. 
Table 3. Impact of genotype, husk-encasement status, and growing year on the productprecursor ratios determined by Bayesian model comparison. The product-precursor relationship was represented by the linear regression of product-precursor ratio $\left(H C_{2 n-1}: F A_{2 n}\right)$ versus the alkyl chain length, $2 n$. Bayesian model comparison was performed on the combined metabolomics datasets gathered from tissue grown in 2014 and 2015.

\begin{tabular}{|c|c|c|c|}
\hline Baseline model & Environment models ${ }^{\mathrm{a}}$ & Examined term & Bayes factor $^{b}$ \\
\hline \multirow{6}{*}{$\begin{array}{l}\text { Genotype }(g)+ \\
\text { Encasement status }(k)+ \\
\text { Growing year }(y)+ \\
\text { Acyl chain length }(n)+ \\
(g \times k)+(g \times y)+(g \times \\
n)+(k \times n)+(k \times y)+ \\
(y \times n)+(g \times k \times n)+ \\
(g \times y \times n)+(k \times y \times n) \\
+(g \times k \times y \times n)\end{array}$} & $\begin{array}{l}k+y+n+(k \times y)+(k \times n)+ \\
(y \times n)+(k \times y \times n)\end{array}$ & Genotype $(g)$ & $1.01 \times 10^{110}$ \\
\hline & $\begin{array}{l}g+y+n+(g \times y)+(g \times n)+ \\
(y \times n)+(g \times y \times n)\end{array}$ & Growing year $(y)$ & $2.35 \times 10^{33}$ \\
\hline & $\begin{array}{l}g+k+n+(g \times k)+(g \times n)+ \\
(k \times n)+(g \times k \times n)\end{array}$ & Encasement Status $(k)$ & $7.76 \times 10^{28}$ \\
\hline & $\begin{array}{l}g+k+y+n+(g \times n)+(k \times n) \\
+(k \times y)+(y \times n)+(k \times y \times n)\end{array}$ & $g \times k$ & $8.80 \times 10^{7}$ \\
\hline & $\begin{array}{l}g+k+y+n+(g \times k)+(g \times n) \\
+(k \times n)+(k \times y)+(y \times n)+ \\
(g \times k \times n)+(k \times y \times n)\end{array}$ & $g \times y$ & $3.52 \times 10^{6}$ \\
\hline & $\begin{array}{l}g+k+y+n+(g \times k)+(g \times y) \\
+(g \times n)+(k \times n)+(y \times n)+ \\
(g \times k \times n)+(g \times y \times n)\end{array}$ & $k \times y$ & $5.49 \times 10^{-9}$ \\
\hline
\end{tabular}

${ }^{a}$ For each modified model, the main effect of the examined term and the associated interaction effects were removed from the baseline model.

$810{ }^{\mathrm{b}}$ Bayes factors were calculated as the ratio of likelihood between the baseline model (numerator) 811 and modified models (denominator). A Bayes factor $>3.2$ indicates that the removal of the 812 examined terms from the baseline model resulted in significantly worse fit to the data. Examined 813 terms are therefore listed in descending order of importance to the model. 


\section{FIGURE LEGENDS}

\section{Figure 1. Spatio-temporal cuticular lipid profiles of maize silks from inbreds Mo17 and}

820 B73, and their reciprocal hybrids. (A) Concentrations of total cuticular lipids and individual

821 lipid classes from silks harvested 3-days post-silk emergence and cut into five allometric sections,

822 A-E (see Methods). The bold dashed line depicts the transition point between husk-encased

823 (sections A, B and C) and emerged (sections D and E) portions of the silks. For each genotype,

824 the changes in concentration of each lipid class along the A to E gradient were fitted to a

825 quadratic regression model. The resulting $\mathrm{R}^{2}$ values are listed and the associated $\mathrm{p}$-values are

826 denoted by asterisks $(* * *, p<0.0001 ; * *, p<0.001 ; *, p<0.05)$. Different letters associated with

827 data bars of the same color denote a statistically significant difference in accumulation between

828 silk sections within a genotype ( $\mathrm{p}<0.05$; Tukey’s Honestly Significant Difference (HSD) test).

829 Seven to eight replicates were evaluated per combination of genotype and silk section,

830 constituting a total sample size of 158. (B) Relative compositions of cuticular lipids along the

831 silk length. Proportion of each cuticular lipid class relative to total cuticular lipid accumulation.

832 Aldehydes and alcohols comprise $<1 \%$ of cuticular lipid metabolome and are not depicted in the

833 figure. Alkenes are comprised predominantly of 7- and 9-monoene classes, and " $>9$ " constituents

834 that include 14- and 15-monoenes, and two dienes. Different letters within data bars for a given

835 genotype denote a statistically significant difference in lipid relative abundance between silk

836 sections for a given metabolite class ( $\mathrm{p}<0.05$; Tukey’s HSD test). (C) Principal component

837 analysis (PCA) of cuticular lipid metabolite abundances among different silk sections. Each data

838 point, which represents the concentrations of the 45 cuticular lipid metabolites profiled from

839 each silk sample, is labeled by silk section (A-E) and color-coded according to genotype.

840 Percentages represent the amounts of variance explained by the first and second principal 
841 components (PC1 and PC2). Ovals represent 95\% confidence ellipses for emerged and husk-

842 encased samples.

843

844 Figure 2. Correlation-based clustering of silk cuticular lipid abundance data for inbred

845 lines, B73 and Mo17. Rank-based Spearman correlations were calculated between all pairs of

846 metabolites and used to construct the weighted correlation networks via WGCNA for A, B73 and

847 BC, Mo17. The non-clustered metabolites for B73 and Mo17 are shown in D and E, respectively.

848 Pairs of lipid metabolites connected by edges are significantly correlated with correlation

849 coefficients $\geq 0.5$ and reside within the same cluster. Edge length represents correlation strength

850 with shorter edges representing stronger correlations between metabolites. Unclustered singleton

851 metabolites were not statistically correlated with any other metabolites, or shared correlation

852 values $<0.5$.

853

854 Figure 3. Accumulation patterns of signature cuticular lipid metabolites that distinguish

855 among genotypes or among silk sections. Concentrations of signature cuticular lipids identified

856 by partial least square discriminant analysis (PLS-DA) as having variable-importance-in-

857 projection (VIP) scores $>1$. Nine (A) and fifteen (B) of these metabolites contribute to either the

858 observed genotype-based or silk section-based PLS-DA separation, respectively, and an

859 additional six lipid metabolites were selected in both categories (C). Two-way ANOVA of the

860 main effects of genotype and silk section were conducted for each metabolite, and statistical

861 significance is noted with asterisks $(* * *, p<0.0001)$ for genotype $(\mathrm{G})$, silk section $(\mathrm{S})$ or both $\mathrm{G}$

862 and $\mathrm{S}$. The interaction effect, $\mathrm{G} \times \mathrm{S}$ was also evaluated by ANOVA for each metabolite and 
863 presented in Supplementary Table S3. Averages \pm SE are reported, with averages connected by

864 colored lines to facilitate visualization.

Figure 4. Accumulation of three VLCFA pools along the silk spatio-temporal gradient.

867 Concentrations of individual cuticular VLCFAs (A), cellular free VLCFAs (B) and cellular lipid-

868 associated VLCFAs $(\mathbf{C})$ in different silk sections of inbred lines B73 (black data points) and

869 Mo17 (red data points). For each genotype, different letters associated with data points indicate

870 statistical differences among silk sections ( $\mathrm{p}<0.05$; Tukey’s HSD). Asterisks denote statistical

871 differences between genotypes at a specific position along the silk length $(* * *, p<0.0001 ; * *, p$

$\left.872<0.001 ;^{*}, \mathrm{p}<0.05\right)$. Averages \pm SE from three to four replicates are reported for the VLCFA

873 pools; $\mathrm{N}=35$.

874

875 Figure 5. Accumulation of cuticular hydrocarbon products and corresponding cuticular

876 VLCFAs, and the regression of the product-precursor ratios on chain length for inbreds

877 B73 and Mo17. Concentrations (log-scaled) of cuticular hydrocarbons $\left(H C_{2 n-1: 0}\right)$ and VLCFAs

$878\left(F A_{2 n: 0}\right)$ were analyzed from husk-encased silks $(\mathbf{A})$ and from silks that had emerged from the

879 husks (B) of the inbreds B73 (black data points) and Mo17 (red data points). Averages \pm SE

880 from seven to eight replicates are reported for the metabolite concentrations. Different letters

881 associated with data points from the same metabolite class indicate a statistically significant

882 difference between acyl chain lengths ( $\mathrm{p}<0.05$; Tukey's HSD test); letters associated with

883 VLCFAs are underlined. In the regression, the prediction intervals for the regression models are

884 indicated by the dashed lines for each inbred. 


\section{LITERATURE CITED}

887

888

Allard A, Bink MCAM, Martinez S, Kelner J-J, Legave J-M, di Guardo M, Di Pierro EA, Laurens F, van de Weg EW, Costes E (2016) Detecting QTLs and putative candidate genes involved in budbreak and flowering time in an apple multiparental population. J Exp Bot 67: $2875-2888$

Allwood JW, Chandra S, Xu Y, Dunn WB, Correa E, Hopkins L, Goodacre R, Tobin AK, Bowsher CG (2015) Profiling of spatial metabolite distributions in wheat leaves under normal and nitrate limiting conditions. Phytochemistry 115: 99-111

Angelovici R, Batushansky A, Deason N, Gonzalez-Jorge S, Gore MA, Fait A, DellaPenna D (2017) Network-guided GWAS improves identification of genes affecting free amino acids. Plant Physiol 173: 872-886

Baldauf J, Marcon C, Paschold A, Hochholdinger F (2016) Nonsyntenic genes drive tissuespecific dynamics of differential, nonadditive and allelic expression patterns in maize hybrids. Plant Physiol 171: 1144-11556

Bartel J, Krumsiek J, Theis FJ (2013) Statistical methods for the analysis of high-throughput metabolomics data. Comput Struct Biotechnol J 4: e201301009

Bartzis G, Deelen J, Maia J, Ligterink W, Hilhorst HWM, Houwing-Duistermaat J-J, van Eeuwijk F, Uh H-W (2017) Estimation of metabolite networks with regard to a specific covariable: applications to plant and human data. Metabolomics 13: 129

Bernard A, Domergue F, Pascal S, Jetter R, Renne C, Faure J-D, Haslam RP, Napier JA, Lessire R, Joubès J (2012) Reconstitution of plant alkane biosynthesis in yeast demonstrates that Arabidopsis ECERIFERUM1 and ECERIFERUM3 are core components of a very-longchain alkane synthesis complex. Plant Cell 24: 3106-18 
909

910

911

912

913

914

915

916

917

918

919

920

921

922

923

924

925

926

927

928

929

930

931

Bianchi A, Bianchi G, Avato P, Salamini F (1985) Biosynthetic pathways of epicuticular wax of maize as assessed by mutation, light, plant-age and inhibitor studies. Maydica 30: 179-198

Bianchi G, Avato P, Salamini F (1984) Surface waxes from grain, leaves, and husks of maize (Zea mays L.). Cereal Chem 61: 45-47

Blacklock BJ, Jaworski JG (2006) Substrate specificity of Arabidopsis 3-ketoacyl-CoA synthases. Biochem Biophys Res Commun 346: 583-590

Bourgault R, Matschi S, Vasquez M, Qiao P, Sonntag A, Charlebois C, Mohammadi M, Scanlon MJ, Smith LG, Molina I (2020) Constructing functional cuticles: analysis of relationships between cuticle lipid composition, ultrastructure and water barrier function in developing adult maize leaves. Ann Bot 125: 79-91

Busta L, Hegebarth D, Kroc E, Jetter R (2017) Changes in cuticular wax coverage and composition on developing Arabidopsis leaves are influenced by wax biosynthesis gene expression levels and trichome density. Planta 245: 297-311

Campbell AA, Stenback KE, Flyckt K, Hoang T, Perera MAD, Nikolau BJ (2019) A single-cell platform for reconstituting and characterizing fatty acid elongase component enzymes. PLoS One 14: e0213620

Cheesbrough TM, Kolattukudy PE (1984) Alkane biosynthesis by decarbonylation of aldehydes catalyzed by a particulate preparation from Pisum sativum. Proc Natl Acad Sci 81: 66136617

Dennison T, Qin W, Loneman DM, Condon SGF, Lauter N, Nikolau BJ, Yandeau-Nelson MD (2019) Genetic and environmental variation impact the cuticular hydrocarbon metabolome on the stigmatic surfaces of maize. BMC Plant Biol 19: 430

Dietrich CR, Perera MADN, D. Yandeau-Nelson M, Meeley RB, Nikolau BJ, Schnable PS 

component of fatty acid elongase is essential for maize (Zea mays L.) development. Plant J 42: 844-861

935 DiLeo M V., Strahan GD, den Bakker M, Hoekenga OA (2011) Weighted correlation network analysis (WGCNA) applied to the tomato fruit metabolome. PLoS One 6: e26683 spatial resolution mass spectrometry imaging reveals the genetically programmed, developmental modification of the distribution of thylakoid membrane lipids among

Eigenbrode SD, Espelie KE (1995) Effects of Plant Epicuticular Lipids on Insect Herbivores. Annu Rev Entomol 40: 171-194 gene identical to CUT1, differentially affect long-chain lipid content on the surface of

949 French KE, Harvey J, McCullagh JSO (2018) Targeted and untargeted metabolic profiling of wild grassland plants identifies antibiotic and anthelmintic compounds targeting pathogen

952 Fuad-Hassan A, Tardieu F, Turc O (2008) Drought-induced changes in anthesis-silking interval 953 are related to silk expansion: a spatio-temporal growth analysis in maize plants subjected to 954 soil water deficit. Plant Cell Environ 31: 1349-60 
955 Fukushima A, Kusano M, Redestig H, Arita M, Saito K (2011) Metabolomic correlation-network

956 modules in Arabidopsis based on a graph-clustering approach. BMC Syst Biol 5: 1

957 Gonzalo M, Vyn TJ, Holland JB, McIntyre LM (2007) Mapping reciprocal effects and

958 interactions with plant density stress in Zea mays L. Heredity (Edinb) 99: 14-30

959 Di Guardo M, Bink MCAM, Guerra W, Letschka T, Lozano L, Busatto N, Poles L, Tadiello A,

960 Bianco L, Visser RGF, et al (2017) Deciphering the genetic control of fruit texture in apple

961 by multiple family-based analysis and genome-wide association. J Exp Bot 68: 1451-1466

962 Hegebarth D, Buschhaus C, Joubès J, Thoraval D, Bird D, Jetter R (2017) Arabidopsis ketoacyl-

963 CoA synthase $16(\mathrm{KCS} 16)$ forms $\mathrm{C}_{36} / \mathrm{C}_{38}$ acyl precursors for leaf trichome and pavement

964 surface wax. Plant Cell Environ 40: 1761-1776

965 Hegebarth D, Buschhaus C, Wu M, Bird D, Jetter R (2016) The composition of surface wax on

966 trichomes of Arabidopsis thaliana differs from wax on other epidermal cells. Plant J 88:

$967 \quad 762-774$

968 Hong J, Yang L, Zhang D, Shi J (2016) Plant metabolomics: an indispensable system biology

969 tool for plant science. Int J Mol Sci 17: 767

970 Horvath S, Langfelder P (2011) Tutorial for the WGCNA package for R: III. Using: 5.

$971 \quad$ Construction of a weighted gene co-expression $n$

972 Howard RW, Lord JC (2003) Cuticular lipids of the booklouse, Liposcelis bostrychophila:

973 hydrocarbons, aldehydes, fatty acids, and fatty acid amides. J Chem Ecol 29: 615-627

974 Jetter R, Kunst L, Samuels A (2006) Composition of plant cuticular waxes. In M Riederer, C

975 Müller, eds, Biol. Plant Cuticle. Blackwell, Oxford, pp 145-181

976 Jetter R, Kunst L, Samuels AL (2018) Composition of Plant Cuticular Waxes. Annu. Plant Rev.

977 online. John Wiley \& Sons, Ltd, Chichester, UK, pp 145-181 
978 Joubès J, Raffaele S, Bourdenx B, Garcia C, Laroche-Traineau J, Moreau P, Domergue F,

979 Lessire R (2008) The VLCFA elongase gene family in Arabidopsis thaliana: phylogenetic

980 analysis, 3D modelling and expression profiling. Plant Mol Biol 67: 547-566

981 Kang Z, Babar MA, Khan N, Guo J, Khan J, Islam S, Shrestha S, Shahi D (2019) Comparative

982 metabolomic profiling in the roots and leaves in contrasting genotypes reveals complex

983 mechanisms involved in post-anthesis drought tolerance in wheat. PLoS One 14: e0213502

984 Kim J, Jung JH, Lee SB, Go YS, Kim HJ, Cahoon R, Markham JE, Cahoon EB, Suh MC (2013)

985 Arabidopsis 3-Ketoacyl-Coenzyme A synthase9 is involved in the synthesis of tetracosanoic

986 acids as precursors of cuticular waxes, suberins, sphingolipids, and phospholipids. Plant

$987 \quad$ Physiol 162: 567-580

988 Kim KS, Park SH, Jenks MA (2007a) Changes in leaf cuticular waxes of sesame (Sesamum

989 indicum L.) plants exposed to water deficit. J Plant Physiol 164: 1134-1143

990 Kim KS, Park SH, Kim DK, Jenks MA (2007b) Influence of water deficit on leaf cuticular

991 waxes of soybean (Glycine max [L.] Merr.). Int J Plant Sci 168: 307-316

992 KRAUSS P, MARKSTADTER C, RIEDERER M (1997) Attenuation of UV radiation by plant

993 cuticles from woody species. Plant, Cell Environ 20: 1079-1085

994 Lai C, Kunst L, Jetter R (2007) Composition of alkyl esters in the cuticular wax on inflorescence

995 stems of Arabidopsis thaliana cer mutants. Plant J 50: 189-196

996 Langfelder P, Horvath S (2008) WGCNA: an R package for weighted correlation network

997 analysis. BMC Bioinformatics 9: 559

998 Li D, Heiling S, Baldwin IT, Gaquerel E (2016) Illuminating a plant's tissue-specific metabolic

999 diversity using computational metabolomics and information theory. Proc Natl Acad Sci

1000 113: E7610-E7618 
1001

1002

1003

1004

1005

1006

1007

1008

1009

1010

1011

1012

1013

1014

1015

1016

1017

1018

1019

1020

1021

1022

1023

Li W, Zhang H, Li X, Zhang F, Liu C, Du Y, Gao X, Zhang Z, Zhang X, Hou Z, et al (2017)

Intergrative metabolomic and transcriptomic analyses unveil nutrient remobilization events in leaf senescence of tobacco. Sci Rep 7: 12126

Loneman DM, Peddicord L, Al-Rashid A, Nikolau BJ, Lauter N, Yandeau-Nelson MD (2017) A robust and efficient method for the extraction of plant extracellular surface lipids as applied to the analysis of silks and seedling leaves of maize. PLoS One 12: e0180850

Luo B, Ma P, Nie Z, Zhang X, He X, Ding X, Feng X, Lu Q, Ren Z, Lin H, et al (2019)

Metabolite profiling and genome-wide association studies reveal response mechanisms of phosphorus deficiency in maize seedling. Plant J 97: 947-969

Marcon C, Paschold A, Malik WA, Lithio A, Baldauf JA, Altrogge L, Opitz N, Lanz C, Schoof H, Nettleton D, et al (2017) Stability of single-parent gene expression complementation in maize hybrids upon water deficit stress. Plant Physiol 173: 1247-1257

Marttinen P, Pirinen M, Sarin A-P, Gillberg J, Kettunen J, Surakka I, Kangas AJ, Soininen P, O’Reilly P, Kaakinen M, et al (2014) Assessing multivariate gene-metabolome associations with rare variants using Bayesian reduced rank regression. Bioinformatics 30: 2026-2034

McNinch C, Chen K, Dennison T, Lopez M, Yandeau-Nelson MD, Lauter N (2020) A multigenotype maize silk expression atlas reveals how exposure-related stresses are mitigated following emergence from husk leaves. Plant Genome. doi: 10.1002/tpg2.20040

Michaelson L V., Napier JA, Molino D, Faure J-D (2016) Plant sphingolipids: Their importance in cellular organization and adaption. Biochim Biophys Acta - Mol Cell Biol Lipids 1861: $1329-1335$

Millar AA, Kunst L (1997) Very-long-chain fatty acid biosynthesis is controlled through the expression and specificity of the condensing enzyme. Plant J 12: 121-131 
1024 Miller SS, Reid LM, Butler G, Winter SP, McGoldrick NJ (2003) Long chain alkanes in silk

1025 extracts of maize genotypes with varying resistance to fusarium graminearum. J Agric Food

$1026 \quad$ Chem 51:6702-6708

1027 Montesinos-López A, Montesinos-López OA, Cuevas J, Mata-López WA, Burgueño J, Mondal

1028 S, Huerta J, Singh R, Autrique E, González-Pérez L, et al (2017) Genomic Bayesian

1029 functional regression models with interactions for predicting wheat grain yield using hyper-

$1030 \quad$ spectral image data. Plant Methods 13: 62

1031 Nakamura Y (2017) Plant phospholipid diversity: emerging functions in metabolism and

1032 protein-lipid interactions. Trends Plant Sci 22: 1027-1040

1033 Obata T, Witt S, Lisec J, Palacios-Rojas N, Florez-Sarasa I, Araus JL, Cairns JE, Yousfi S,

1034 Fernie AR (2015) Metabolite profiles of maize leaves in drought, heat and combined stress

1035 field trials reveal the relationship between metabolism and grain yield. Plant Physiol

$1036 \quad$ pp.01164.2015

1037 Papazian S, Khaling E, Bonnet C, Lassueur S, Reymond P, Moritz T, Blande JD, Albrectsen BR

1038 (2016) Central metabolic responses to ozone and herbivory affect photosynthesis and

1039 stomatal closure. Plant Physiol 172: 2057-2078

1040 Pascal S, Bernard A, Deslous P, Gronnier J, Fournier-Goss A, Domergue F, Rowland O, Joubès

1041 J (2019) Arabidopsis CER1-LIKE1 functions in a cuticular very-long-chain alkane-forming

$1042 \quad$ complex. Plant Physiol 179: 415-432

1043 Paschold A, Jia Y, Marcon C, Lund S, Larson NB, Yeh C-T, Ossowski S, Lanz C, Nettleton D,

1044 Schnable PS, et al (2012) Complementation contributes to transcriptome complexity in

1045 maize (Zea mays L.) hybrids relative to their inbred parents. Genome Res 22: 2445-2454

1046 Paultre DSG, Gustin M-P, Molnar A, Oparka KJ (2016) Lost in transit: long-distance trafficking 

and phloem unloading of protein signals in arabidopsis homografts. Plant Cell 28: 20162025

1049 Perera MADN, Qin W, Yandeau-Nelson M, Fan L, Dixon P, Nikolau BJ (2010) Biological

1050 origins of normal-chain hydrocarbons: a pathway model based on cuticular wax analyses of $1051 \quad$ maize silks. Plant J 64: 618-632

1052 Pérez-Enciso M, Tenenhaus M (2003) Prediction of clinical outcome with microarray data: a 1053 partial least squares discriminant analysis (PLS-DA) approach. Hum Genet 112: 581-92

1054 Pick TR, Bräutigam A, Schlüter U, Denton AK, Colmsee C, Scholz U, Fahnenstich H, 1055 Pieruschka R, Rascher U, Sonnewald U, et al (2011) Systems analysis of a maize leaf 1056 developmental gradient redefines the current $\mathrm{C} 4$ model and provides candidates for 1057 regulation. Plant Cell 23: 4208-4220

1058 Racovita RC, Jetter R (2016) Identification of in-chain-functionalized compounds and methyl1059 branched alkanes in cuticular waxes of Triticum aestivum cv. Bethlehem. PLoS One 11: $1060 \quad \mathrm{e} 0165827$

1061 Rao J, Cheng F, Hu C, Quan S, Lin H, Wang J, Chen G, Zhao X, Alexander D, Guo L, et al 1062 (2014) Metabolic map of mature maize kernels. Metabolomics 10: 775-787

1063 Rhee Y, Hlousek-Radojcic A, Ponsamuel J, Liu D, Post-Beittenmiller D (1998) Epicuticular wax 1064 accumulation and fatty acid elongation activities are induced during leaf development of 1065 leeks. Plant Physiol 116: 901-911

1066 Riederer M, Schreiber L (2001) Protecting against water loss: analysis of the barrier properties of 1067 plant cuticles. J Exp Bot 52: 2023-2032

1068 Rosato A, Tenori L, Cascante M, De Atauri Carulla PR, Martins dos Santos VAP, Saccenti E 1069 (2018) From correlation to causation: analysis of metabolomics data using systems biology 
approaches. Metabolomics 14: 37

1071

1072

1073

1074

1075

1076

1077

1078

1079

1080

1081

1082

1083

1084

1085

1086

1087

1088

1089

1090

1091

1092

Samuels L, Kunst L, Jetter R (2008) Sealing plant surfaces: cuticular wax formation by epidermal cells. Annu Rev Plant Biol 59: 683-707

Sato N, Awai K (2017) "Prokaryotic pathway" is not prokaryotic: noncyanobacterial origin of the chloroplast lipid biosynthetic pathway revealed by comprehensive phylogenomic analysis. Genome Biol Evol 9: 3162-3178

Sawada Y, Akiyama K, Sakata A, Kuwahara A, Otsuki H, Sakurai T, Saito K, Hirai MY (2009) Widely targeted metabolomics based on large-scale MS/MS data for elucidating metabolite accumulation patterns in plants. Plant Cell Physiol 50: 37-47

Serrano M, Coluccia F, Torres M, L'Haridon F, Métraux J-P (2014) The cuticle and plant defense to pathogens. Front Plant Sci. doi: 10.3389/fpls.2014.00274

Shen M, Broeckling CD, Chu EY, Ziegler G, Baxter IR, Prenni JE, Hoekenga OA (2013) Leveraging non-targeted metabolite profiling via statistical genomics. PLoS One 8: e57667 Shepherd T, Wynne Griffiths D (2006) The effects of stress on plant cuticular waxes. New Phytol 171: 469-499

Steuer R (2006) Review: On the analysis and interpretation of correlations in metabolomic data. Brief Bioinform 7: 151-158

Sulpice R, Pyl E-T, Ishihara H, Trenkamp S, Steinfath M, Witucka-Wall H, Gibon Y, Usadel B, Poree F, Piques MC, et al (2009) Starch as a major integrator in the regulation of plant growth. Proc Natl Acad Sci 106: 10348-10353

Swanson-Wagner RA, DeCook R, Jia Y, Bancroft T, Ji T, Zhao X, Nettleton D, Schnable PS (2009) Paternal dominance of trans-eQTL influences gene expression patterns in maize hybrids. Science 326: 1118-1120 
1093 Tarpley L, Duran AL, Kebrom TH, Sumner LW (2005) Biomarker metabolites capturing the 1094 metabolite variance present in a rice plant developmental period. BMC Plant Biol 5: 8

1095 Toubiana D, Xue W, Zhang N, Kremling K, Gur A, Pilosof S, Gibon Y, Stitt M, Buckler ES, 1096 Fernie AR, et al (2016) Correlation-based network analysis of metabolite and enzyme profiles reveals a role of citrate biosynthesis in modulating $\mathrm{N}$ and $\mathrm{C}$ metabolism in Zea mays. Front Plant Sci. doi: 10.3389/fpls.2016.01022 Developmental and environmental regulation of cuticular wax biosynthesis in fleshy fruits. Front Plant Sci. doi: 10.3389/fpls.2019.00431

Wang DR, Guadagno CR, Mao X, Mackay DS, Pleban JR, Baker RL, Weinig C, Jannink J-L,

1105 Warth B, Parich A, Bueschl C, Schoefbeck D, Neumann NKN, Kluger B, Schuster K, Krska R, Adam G, Lemmens M, et al (2015) GC-MS based targeted metabolic profiling identifies changes in the wheat metabolome following deoxynivalenol treatment. Metabolomics 11: Ewers BE (2019) A framework for genomics-informed ecophysiological modeling in plants. J Exp Bot 70: 2561-2574

1113 Wen M, Jetter R (2009) Composition of secondary alcohols, ketones, alkanediols, and ketols in 1114 Arabidopsis thaliana cuticular waxes. J Exp Bot 60: 1811-1821

1115 Worley B, Powers R (2012) Multivariate analysis in metabolomics. Curr Metabolomics 1: 92- 
$1116 \quad 107$

1117 Xue D, Zhang X, Lu X, Chen G, Chen Z-H (2017) Molecular and evolutionary mechanisms of

1118 cuticular wax for plant drought tolerance. Front Plant Sci. doi: 10.3389/fpls.2017.00621

1119 Yandeau-Nelson M (2015) Advances in metabolomic applications in plant genetics and breeding.

1120 CAB Rev Perspect Agric Vet Sci Nutr Nat Resour. doi: 10.1079/PAVSNNR201510040

1121 Yang G, Wiseman BR, Espelie KE (1992) Cuticular lipids from silks of seven corn genotypes

1122 and their effect on development of corn earworm larvae [Helicoverpa zea (Boddie)]. J Agric

$1123 \quad$ Food Chem 40: 1058-1061

1124 Yeats TH, Rose JKC (2013) The Formation and Function of Plant Cuticles. Plant Physiol 163:

$1125 \quad 5-20$

1126 Zhou S, Kremling KA, Bandillo N, Richter A, Zhang YK, Ahern KR, Artyukhin AB, Hui JX,

1127 Younkin GC, Schroeder FC, et al (2019) Metabolome-scale genome-wide association

1128 studies reveal chemical diversity and genetic control of maize specialized metabolites. Plant

$1129 \quad$ Cell 31: 937-955

1130

1131 


\begin{tabular}{|lll|}
\hline$\square$ Hydrocarbons $\square$ VLCFAs $\quad \square$ Aldehydes $\square$ Alcohols \\
\hline
\end{tabular}
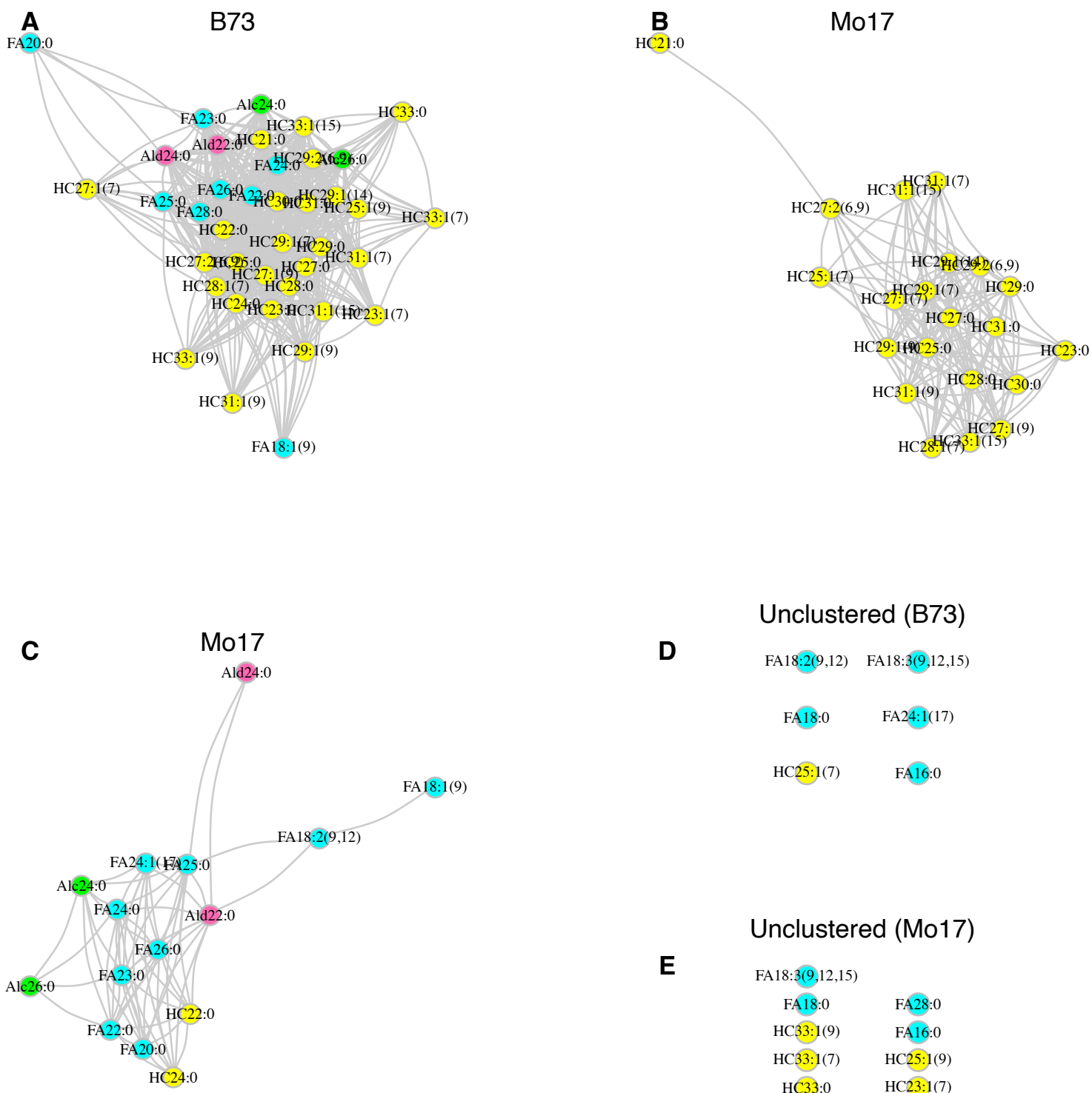

D

Unclustered (B73)

FA18:2(9,12) $\quad$ FA18:3(9,12,15)

FA18:0 FA24:1(17)

HC25:1(7) FA16:0

Unclustered (Mo17)

E

$\begin{array}{cc}\text { FA18:3(9,12,15) } & \\ \text { FA18:0 } & \text { FA28:0 } \\ \text { HC33:1(9) } & \text { FA16:0 } \\ \text { HC33:1(7) } & \text { HC25:1(9) } \\ \text { HC33:0 } & \text { HC23:1(7) }\end{array}$

Figure 2. Correlation-based clustering of silk cuticular lipid abundance data for inbred lines, B73 and Mo17. Rank-based Spearman correlations were calculated between all pairs of metabolites and used to construct the weighted correlation networks via WGCNA for $\mathbf{A}$, B73 and BC, Mo17. The non-clustered metabolites for B73 and Mo17 are shown in D and E, respectively. Pairs of lipid metabolites connected by edges are significantly correlated with correlation coefficients $\geq 0.5$ and reside within the same cluster. Edge length represents correlation strength with shorter edges representing stronger correlations between metabolites. Unclustered singleton metabolites were not statistically correlated with any other metabolites, or shared correlation values $<0.5$. 

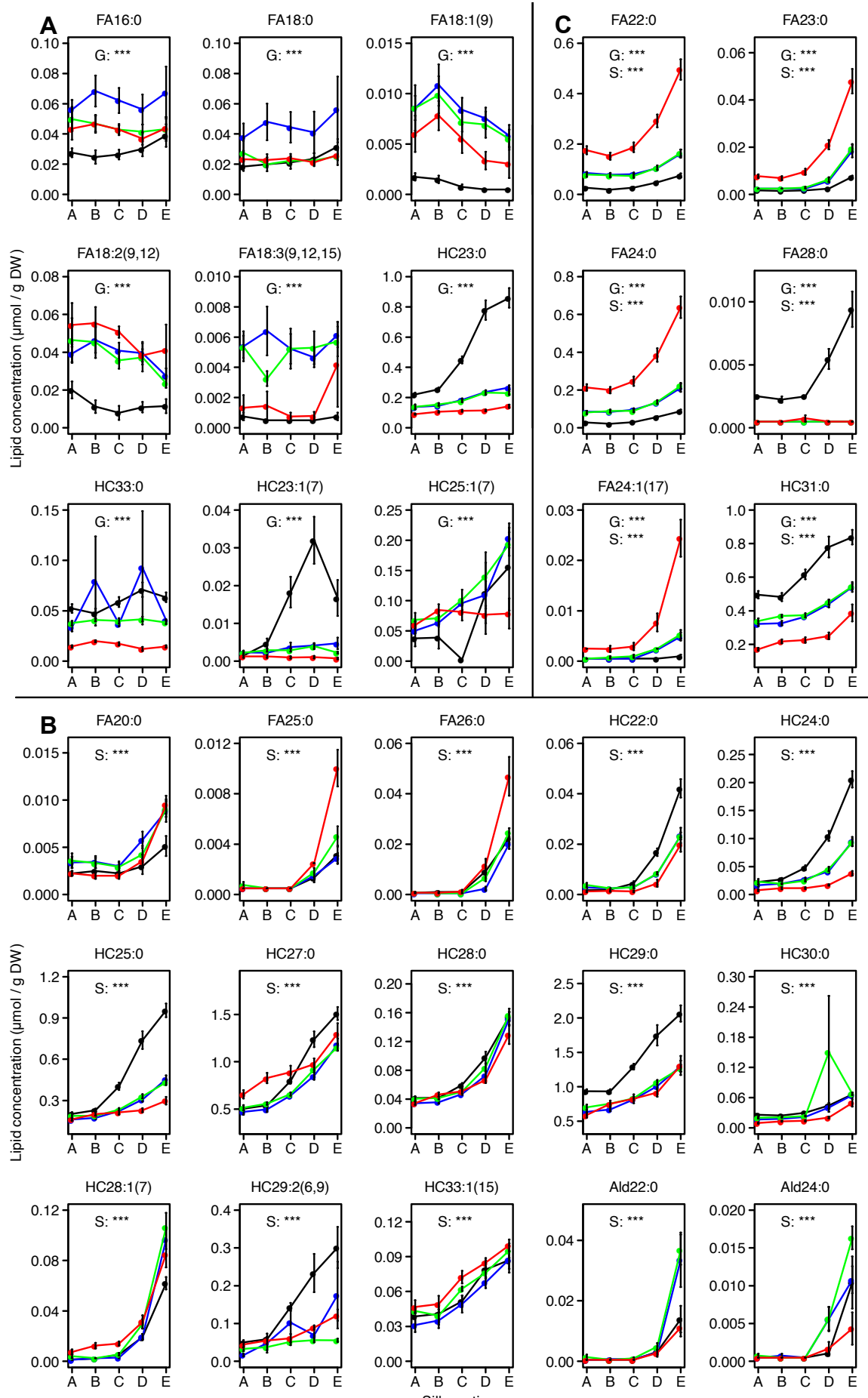

\section{Fig. 3 Accumulation patterns of signature cuticular lipid}

\section{metabolites that distinguish among genotypes or among silk}

sections. Concentrations of signature cuticular lipids identified by

partial least square discriminant analysis (PLS-DA) as having variableimportance-in-projection (VIP) scores $>1$. Nine (A) and fifteen (B) of these metabolites contribute to either the observed genotype-based or silk section-based PLS-DA separation, respectively, and an additional six lipid metabolites were selected in both categories (C). Two-way ANOVA of the main effects of genotype and silk section were conducted for each metabolite, and statistical significance is noted with asterisks $(* * *, p<0.0001)$ for genotype $(\mathrm{G})$, silk section $(\mathrm{S})$ or both $\mathrm{G}$ and $\mathrm{S}$. The interaction effect, $\mathrm{G} \times \mathrm{S}$ was also evaluated by ANOVA for each metabolite and presented in Supplementary Table S3. Averages \pm $\mathrm{SE}$ are reported, with averages connected by colored lines to facilitate visualization. 

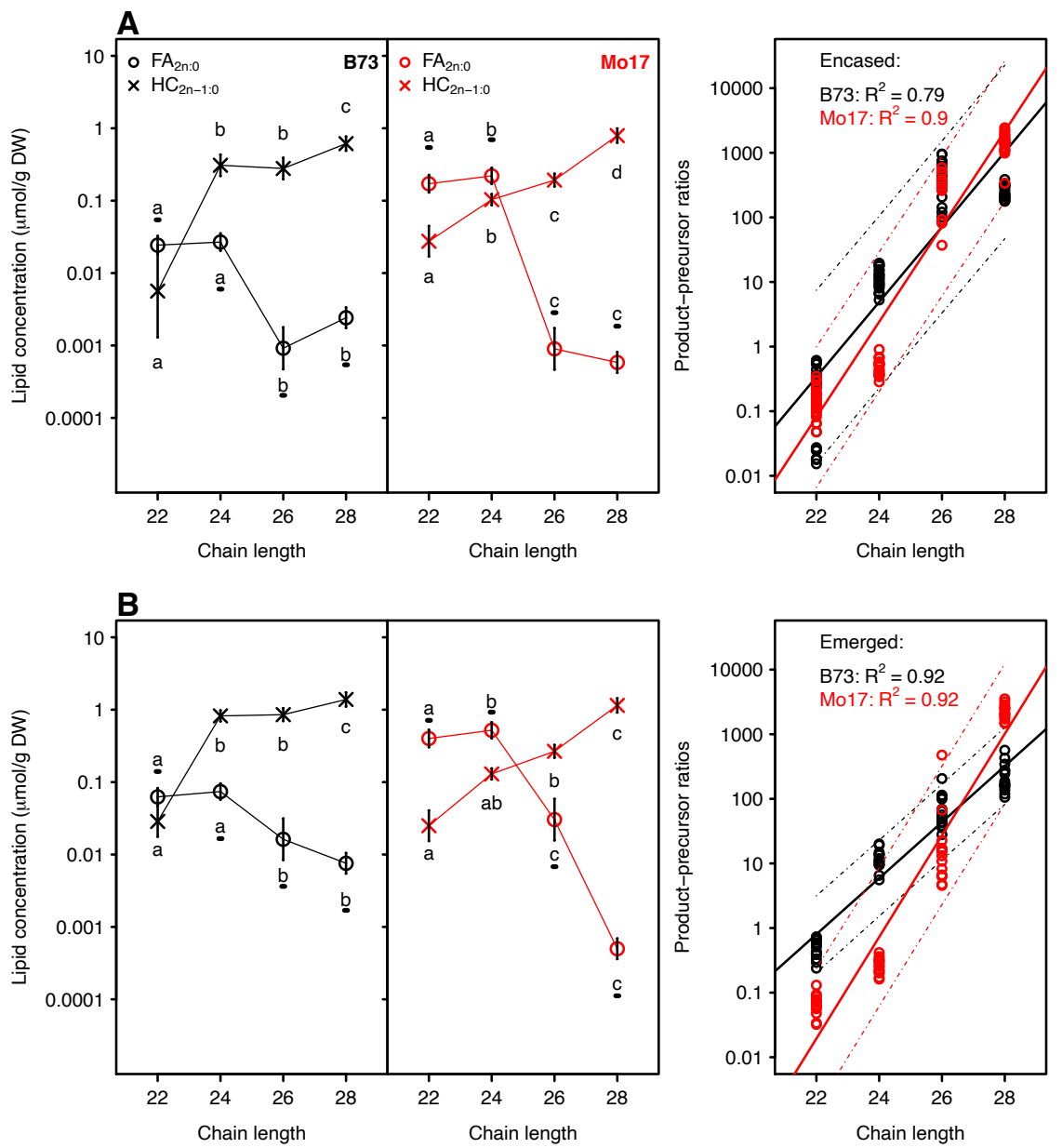

Figure 5. Accumulation of cuticular hydrocarbon products and corresponding cuticular VLCFAs, and the regression of the product-precursor ratios on chain length for inbreds $B 73$ and Mo17. Concentrations (log-scaled) of cuticular hydrocarbons $\left(H C_{2 n-1: 0}\right)$ and VLCFAs $\left(F A_{2 n: 0}\right)$ were analyzed from husk-encased silks $(\mathbf{A})$ and from silks that had emerged from the husks (B) of the inbreds B73 (black data points) and Mo17 (red data points). Averages \pm SE from seven to eight replicates are reported for the metabolite concentrations. Different letters associated with data points from the same metabolite class indicate a statistically significant difference between alkyl chain lengths ( $\mathrm{p}<0.05$; Tukey's HSD test); letters associated with VLCFAs are underlined. In the regression, the prediction intervals for the regression models are indicated by the dashed lines for each inbred. 


\section{Parsed Citations}

Allard A, Bink MCAM, Martinez S, Kelner J-J, Legave J-M, di Guardo M, Di Pierro EA, Laurens F, van de Weg EW, Costes E (2016) Detecting QTLs and putative candidate genes involved in budbreak and flowering time in an apple multiparental population. J Exp Bot 67: 2875-2888

Google Scholar: Author Only Title Only Author and Title

Alwood JW, Chandra S, Xu Y, Dunn WB, Correa E, Hopkins L, Goodacre R, Tobin AK, Bowsher CG (2015) Profiling of spatial metabolite distributions in wheat leaves under normal and nitrate limiting conditions. Phytochemistry 115: 99-111

Google Scholar: Author Only Title Only Author and Title

Angelovici R, Batushansky A, Deason N, Gonzalez-Jorge S, Gore MA, Fait A, DellaPenna D (2017) Network-guided GWAS improves identification of genes affecting free amino acids. Plant Physiol 173: 872-886

Google Scholar: Author Only Title Only Author and Title

Baldauf J, Marcon C, Paschold A, Hochholdinger F (2016) Nonsyntenic genes drive tissue-specific dynamics of differential, nonadditive and allelic expression patterns in maize hybrids. Plant Physiol 171: 1144-11556

Google Scholar: Author Only Title Only Author and Title

Bartel J, Krumsiek J, Theis FJ (2013) Statistical methods for the analysis of high-throughput metabolomics data. Comput Struct Biotechnol J 4: e201301009

Google Scholar: Author Only Title Only Author and Title

Bartzis G, Deelen J, Maia J, Ligterink W, Hilhorst HWM, Houwing-Duistermaat J-J, van Eeuwijk F, Uh H-W(2017) Estimation of metabolite networks with regard to a specific covariable: applications to plant and human data. Metabolomics 13: 129

Google Scholar: Author Only Title Only Author and Title

Bernard A, Domergue F, Pascal S, Jetter R, Renne C, Faure J-D, Haslam RP, Napier JA, Lessire R, Joubès J (2012) Reconstitution of plant alkane biosynthesis in yeast demonstrates that Arabidopsis ECERIFERUM1 and ECERIFERUM3 are core components of a verylong-chain alkane synthesis complex. Plant Cell 24: 3106-18

Google Scholar: Author Only Title Only Author and Title

Bianchi A, Bianchi G, Avato P, Salamini F (1985) Biosynthetic pathways of epicuticular wax of maize as assessed by mutation, light, plant-age and inhibitor studies. Maydica 30: 179-198

Google Scholar: Author Only Title Only Author and Title

Bianchi G, Avato P, Salamini F (1984) Surface waxes from grain, leaves, and husks of maize (Zea mays L.). Cereal Chem 61: 45-47

Google Scholar: Author Only Title Only Author and Title

Blacklock BJ, Jaworski JG (2006) Substrate specificity of Arabidopsis 3-ketoacyl-CoAsynthases. Biochem Biophys Res Commun 346: 583-590

Google Scholar: Author Only Title Only Author and Title

Bourgault R, Matschi S, Vasquez M, Qiao P, Sonntag A, Charlebois C, Mohammadi M, Scanlon MJ, Smith LG, Molina I (2020) Constructing functional cuticles: analysis of relationships between cuticle lipid composition, ultrastructure and water barrier function in developing adult maize leaves. Ann Bot 125: 79-91

Google Scholar: Author Only Title Only Author and Title

Busta L, Hegebarth D, Kroc E, Jetter R (2017) Changes in cuticular wax coverage and composition on developing Arabidopsis leaves are influenced by wax biosynthesis gene expression levels and trichome density. Planta 245: 297-311

Google Scholar: Author Only Title Only Author and Title

Campbell AA Stenback KE, Flyckt K, Hoang T, Perera MAD, Nikolau BJ (2019) A single-cell platform for reconstituting and characterizing fatty acid elongase component enzymes. PLoS One 14: e0213620

Google Scholar: Author Only Title Only Author and Title

Cheesbrough TM, Kolattukudy PE (1984) Akane biosynthesis by decarbonylation of aldehydes catalyzed by a particulate preparation from Pisum sativum Proc Natl Acad Sci 81: 6613-6617

Google Scholar: Author Only Title Only Author and Title

Dennison T, Qin W, Loneman DM, Condon SGF, Lauter N, Nikolau BJ, Yandeau-Nelson MD (2019) Genetic and environmental variation impact the cuticular hydrocarbon metabolome on the stigmatic surfaces of maize. BMC Plant Biol 19: 430

Google Scholar: Author Only Title Only Author and Title

Dietrich CR, Perera MADN, D. Yandeau-Nelson M, Meeley RB, Nikolau BJ, Schnable PS (2005) Characterization of two GL8 paralogs reveals that the 3-ketoacyl reductase component of fatty acid elongase is essential for maize (Zea mays $L$.) development. Plant $J$ 42: 844-861

Google Scholar: Author Only Title Only Author and Title

DiLeo M V., Strahan GD, den Bakker M, Hoekenga OA(2011) Weighted correlation network analysis (WGCNA) applied to the tomato fruit metabolome. PLoS One 6: e26683

Google Scholar: Author Only Title Only Author and Title 
Dueñas ME, Klein AT, Alexander LE, Yandeau-Nelson MD, Nikolau BJ, Lee YJ (2017) High spatial resolution mass spectrometry imaging reveals the genetically programmed, developmental modification of the distribution of thylakoid membrane lipids among individual cells of maize leaf. Plant J 89: 825-838

Google Scholar: Author Only Title Only Author and Title

Eigenbrode SD, Espelie KE (1995) Effects of Plant Epicuticular Lipids on Insect Herbivores. Annu Rev Entomol 40: 171-194

Google Scholar: Author Only Title Only Author and Title

Fernandez O, Urrutia M, Bernillon S, Giauffret C, Tardieu F, Le Gouis J, Langlade N, Charcosset A, Moing A, Gibon Y (2016) Fortune telling: metabolic markers of plant performance. Metabolomics 12: 158

Google Scholar: Author Only Title Only Author and Title

Fiebig A, Mayfield JA, Miley NL, Chau S, Fischer RL, Preuss D (2000) Atterations in CER6 a gene identical to CUT1, differentially affect long-chain lipid content on the surface of pollen and stems. Plant Cell 12: 2001-2008

Google Scholar: Author Only Title Only Author and Title

French KE, Harvey J, McCullagh JSO (2018) Targeted and untargeted metabolic profiling of wild grassland plants identifies antibiotic and anthelmintic compounds targeting pathogen physiology, metabolism and reproduction. Sci Rep 8: 1695

Google Scholar: Author Only Title Only Author and Title

Fuad-Hassan A, Tardieu F, Turc O (2008) Drought-induced changes in anthesis-silking interval are related to silk expansion: a spatiotemporal growth analysis in maize plants subjected to soil water deficit. Plant Cell Environ 31: 1349-60

Google Scholar: Author Only Title Only Author and Title

Fukushima A, Kusano M, Redestig H, Arita M, Saito K (2011) Metabolomic correlation-network modules in Arabidopsis based on a graph-clustering approach. BMC Syst Biol 5: 1

Google Scholar: Author Only Title Only Author and Title

Gonzalo M, Vyn TJ, Holland JB, McIntyre LM (2007) Mapping reciprocal effects and interactions with plant density stress in Zea mays L. Heredity (Edinb) 99: 14-30

Google Scholar: Author Only Title Only Author and Title

Di Guardo M, Bink MCAM, Guerra W, Letschka T, Lozano L, Busatto N, Poles L, Tadiello A, Bianco L, Visser RGF, et al (2017) Deciphering the genetic control of fruit texture in apple by multiple family-based analysis and genome-wide association. $\mathrm{J}$ Exp Bot 68 : 1451-1466

Google Scholar: Author Only Title Only Author and Title

Hegebarth D, Buschhaus C, Joubès J, Thoraval D, Bird D, Jetter R (2017) Arabidopsis ketoacyl-CoA synthase 16 (KCS16) forms C36/C38 acyl precursors for leaf trichome and pavement surface wax. Plant Cell Environ 40: 1761-1776

Google Scholar: Author Only Title Only Author and Title

Hegebarth D, Buschhaus C, Wu M, Bird D, Jetter R (2016) The composition of surface wax on trichomes of Arabidopsis thaliana differs from wax on other epidermal cells. Plant $\mathrm{J}$ 88: 762-774

Google Scholar: Author Only Title Only Author and Title

Hong J, Yang L, Zhang D, Shi J (2016) Plant metabolomics: an indispensable system biology tool for plant science. Int J Mol Sci 17: 767 Google Scholar: Author Only Title Only Author and Title

Horvath S, Langfelder P (2011) Tutorial for the WGCNA package for R: Ill. Using: 5. Construction of a weighted gene co-expression n Google Scholar: Author Only Title Only Author and Title

Howard RW, Lord JC (2003) Cuticular lipids of the booklouse, Liposcelis bostrychophila: hydrocarbons, aldehydes, fatty acids, and fatty acid amides. J Chem Ecol 29: 615-627

Google Scholar: Author Only Title Only Author and Title

Jetter R, Kunst L, Samuels A(2006) Composition of plant cuticular waxes. In M Riederer, C Müller, eds, Biol. Plant Cuticle. Blackwell, Oxford, pp 145-181

Google Scholar: Author Only Title Only Author and Title

Jetter R, Kunst L, Samuels AL (2018) Composition of Plant Cuticular Waxes. Annu. Plant Rev. online. John Wiley \& Sons, Ltd, Chichester, UK, pp 145-181

Google Scholar: Author Only Title Only Author and Title

Joubès J, Raffaele S, Bourdenx B, Garcia C, Laroche-Traineau J, Moreau P, Domergue F, Lessire R (2008) The VLCFAelongase gene family in Arabidopsis thaliana: phylogenetic analysis, 3D modelling and expression profiling. Plant Mol Biol 67: $547-566$

Google Scholar: Author Only Title Only Author and Title

Kang Z, Babar MA, Khan N, Guo J, Khan J, Islam S, Shrestha S, Shahi D (2019) Comparative metabolomic profiling in the roots and leaves in contrasting genotypes reveals complex mechanisms involved in post-anthesis drought tolerance in wheat. PLoS One 14: e0213502

Google Scholar: Author Only Title Only Author and Title

Kim J, Jung JH, Lee SB, Go YS, Kim HJ, Cahoon R, Markham JE, Cahoon EB, Suh MC (2013) Arabidopsis 3-Ketoacyl-Coenzyme A synthase 9 is involved in the synthesis of tetracosanoic acids as precursors of cuticular waxes, suberins, sphingolipids, and 
phospholipids. Plant Physiol 162: 567-580

Google Scholar: Author Only Title Only Author and Title

Kim KS, Park SH, Jenks MA (2007a) Changes in leaf cuticular waxes of sesame (Sesamum indicum L.) plants exposed to water deficit. J Plant Physiol 164: 1134-1143

Google Scholar: Author Only Title Only Author and Title

Kim KS, Park SH, Kim DK, Jenks MA (2007b) Influence of water deficit on leaf cuticular waxes of soybean (Glycine max [L.] Merr.). Int J Plant Sci 168: 307-316

Google Scholar: Author Only Title Only Author and Title

KRAUSS P, MARKSTADTER C, RIEDERER M (1997) Attenuation of UV radiation by plant cuticles from woody species. Plant, Cell Environ 20: 1079-1085

Google Scholar: Author Only Title Only Author and Title

Lai C, Kunst L, Jetter R (2007) Composition of alkyl esters in the cuticular wax on inflorescence stems of Arabidopsis thaliana cer mutants. Plant J 50: 189-196

Google Scholar: Author Only Title Only Author and Title

Langfelder P, Horvath S (2008) WGCNA: an R package for weighted correlation network analysis. BMC Bioinformatics 9: 559

Google Scholar: Author Only Title Only Author and Title

Li D, Heiling S, Baldwin IT, Gaquerel E (2016) Illuminating a plant's tissue-specific metabolic diversity using computational metabolomics and information theory. Proc Natl Acad Sci 113: E7610-E7618

Google Scholar: Author Only Title Only Author and Title

Li W, Zhang H, Li X, Zhang F, Liu C, Du Y, Gao X, Zhang Z, Zhang X, Hou Z, et al (2017) Intergrative metabolomic and transcriptomic analyses unveil nutrient remobilization events in leaf senescence of tobacco. Sci Rep 7: 12126

Google Scholar: Author Only Title Only Author and Title

Loneman DM, Peddicord L, A-Rashid A, Nikolau BJ, Lauter N, Yandeau-Nelson MD (2017) A robust and efficient method for the extraction of plant extracellular surface lipids as applied to the analysis of silks and seedling leaves of maize. PLoS One 12: e0180850

Google Scholar: Author Only Title Only Author and Title

Luo B, Ma P, Nie Z, Zhang X, He X, Ding X, Feng X, Lu Q, Ren Z, Lin H, et al (2019) Metabolite profiling and genome-wide association studies reveal response mechanisms of phosphorus deficiency in maize seedling. Plant J 97: 947-969

Google Scholar: Author Only Title Only Author and Title

Marcon C, Paschold A, Malik WA, Lithio A, Baldauf JA, Atrogge L, Opitz N, Lanz C, Schoof H, Nettleton D, et al (2017) Stability of singleparent gene expression complementation in maize hybrids upon water deficit stress. Plant Physiol 173: 1247-1257

Google Scholar: Author Only Title Only Author and Title

Marttinen P, Pirinen M, Sarin AP, Gillberg J, Kettunen J, Surakka I, Kangas AJ, Soininen P, O'Reilly P, Kaakinen M, et al (2014) Assessing multivariate gene-metabolome associations with rare variants using Bayesian reduced rank regression. Bioinformatics 30 : 2026-2034

Google Scholar: Author Only Title Only Author and Title

McNinch C, Chen K, Dennison T, Lopez M, Yandeau-Nelson MD, Lauter N (2020) Amultigenotype maize silk expression atlas reveals how exposure-related stresses are mitigated following emergence from husk leaves. Plant Genome. doi: 10.1002/tpg2.20040

Google Scholar: Author Only Title Only Author and Title

Michaelson L V., Napier JA, Molino D, Faure J-D (2016) Plant sphingolipids: Their importance in cellular organization and adaption.

Biochim Biophys Acta - Mol Cell Biol Lipids 1861: 1329-1335

Google Scholar: Author Only Title Only Author and Title

Millar AA, Kunst L (1997) Very-long-chain fatty acid biosynthesis is controlled through the expression and specificity of the condensing enzyme. Plant J 12: 121-131

Google Scholar: Author Only Title Only Author and Title

Miller SS, Reid LM, Butler G, Winter SP, McGoldrick NJ (2003) Long chain alkanes in silk extracts of maize genotypes with varying resistance to fusarium graminearum J Agric Food Chem 51: 6702-6708

Google Scholar: Author Only Title Only Author and Title

Montesinos-López A, Montesinos-López OA, Cuevas J, Mata-López WA, Burgueño J, Mondal S, Huerta J, Singh R, Autrique E, González-Pérez L, et al (2017) Genomic Bayesian functional regression models with interactions for predicting wheat grain yield using hyper-spectral image data. Plant Methods 13: 62

Google Scholar: Author Only Title Only Author and Title

Nakamura Y (2017) Plant phospholipid diversity: emerging functions in metabolism and protein-lipid interactions. Trends Plant Sci 22: 1027-1040

Google Scholar: Author Only Title Only Author and Title

Obata T, Witt S, Lisec J, Palacios-Rojas N, Florez-Sarasa I, Araus JL, Cairns JE, Yousfi S, Fernie AR (2015) Metabolite profiles of maize 
leaves in drought, heat and combined stress field trials reveal the relationship between metabolism and grain yield. Plant Physiol pp.01164.2015

Google Scholar: Author Only Title Only Author and Title

Papazian S, Khaling E, Bonnet C, Lassueur S, Reymond P, Moritz T, Blande JD, Abrectsen BR (2016) Central metabolic responses to ozone and herbivory affect photosynthesis and stomatal closure. Plant Physiol 172: 2057-2078

Google Scholar: Author Only Title Only Author and Title

Pascal S, Bernard A, Deslous P, Gronnier J, Fournier-Goss A, Domergue F, Rowland O, Joubès J (2019) Arabidopsis CER1-LIKE1 functions in a cuticular very-long-chain alkane-forming complex. Plant Physiol 179: 415-432

Google Scholar: Author Only Title Only Author and Title

Paschold A, Jia Y, Marcon C, Lund S, Larson NB, Yeh C-T, Ossowski S, Lanz C, Nettleton D, Schnable PS, et al (2012)

Complementation contributes to transcriptome complexity in maize (Zea mays L.) hybrids relative to their inbred parents. Genome Res 22: 2445-2454

Google Scholar: Author Only Title Only Author and Title

Paultre DSG, Gustin M-P, Molnar A, Oparka KJ (2016) Lost in transit: long-distance trafficking and phloem unloading of protein signals in arabidopsis homografts. Plant Cell 28: 2016-2025

Google Scholar: Author Only Title Only Author and Title

Perera MADN, Qin W, Yandeau-Nelson M, Fan L, Dixon P, Nikolau BJ (2010) Biological origins of normal-chain hydrocarbons: a pathway model based on cuticular wax analyses of maize silks. Plant J 64: 618-632

Google Scholar: Author Only Title Only Author and Title

Pérez-Enciso M, Tenenhaus M (2003) Prediction of clinical outcome with microarray data: a partial least squares discriminant analysis (PLS-DA) approach. Hum Genet 112: 581-92

Google Scholar: Author Only Title Only Author and Title

Pick TR, Bräutigam A, Schlüter U, Denton AK, Colmsee C, Scholz U, Fahnenstich H, Pieruschka R, Rascher U, Sonnewald U, et al (2011) Systems analysis of a maize leaf developmental gradient redefines the current C4 model and provides candidates for regulation. Plant Cell 23: 4208-4220

Google Scholar: Author Only Title Only Author and Title

Racovita RC, Jetter R (2016) Identification of in-chain-functionalized compounds and methyl-branched alkanes in cuticular waxes of Triticum aestivum cv. Bethlehem. PLoS One 11: e0165827

Google Scholar: Author Only Title Only Author and Title

Rao J, Cheng F, Hu C, Quan S, Lin H, Wang J, Chen G, Zhao X, Alexander D, Guo L, et al (2014) Metabolic map of mature maize kernels. Metabolomics 10: 775-787

Google Scholar: Author Only Title Only Author and Title

Rhee Y, Hlousek-Radojcic A Ponsamuel J, Liu D, Post-Beittenmiller D (1998) Epicuticular wax accumulation and fatty acid elongation activities are induced during leaf development of leeks. Plant Physiol 116: 901-911

Google Scholar: Author Only Title Only Author and Title

Riederer M, Schreiber L (2001) Protecting against water loss: analysis of the barrier properties of plant cuticles. J Exp Bot 52: 20232032

Google Scholar: Author Only Title Only Author and Title

Rosato A Tenori L, Cascante M, De Atauri Carulla PR, Martins dos Santos VAP, Saccenti E (2018) From correlation to causation: analysis of metabolomics data using systems biology approaches. Metabolomics 14: 37

Google Scholar: Author Only Title Only Author and Title

Samuels L, Kunst L, Jetter R (2008) Sealing plant surfaces: cuticular wax formation by epidermal cells. Annu Rev Plant Biol 59: 683-707 Google Scholar: Author Only Title Only Author and Title

Sato N, Awai K (2017) "Prokaryotic pathway" is not prokaryotic: noncyanobacterial origin of the chloroplast lipid biosynthetic pathway revealed by comprehensive phylogenomic analysis. Genome Biol Evol 9: 3162-3178

Google Scholar: Author Only Title Only Author and Title

Sawada Y, Akiyama K, Sakata A, Kuwahara A, Otsuki H, Sakurai T, Saito K, Hirai MY (2009) Widely targeted metabolomics based on large-scale MS/MS data for elucidating metabolite accumulation patterns in plants. Plant Cell Physiol 50: 37-47

Google Scholar: Author Only Title Only Author and Title

Serrano M, Coluccia F, Torres M, L'Haridon F, Métraux J-P (2014) The cuticle and plant defense to pathogens. Front Plant Sci. doi: 10.3389/fpls.2014.00274

Google Scholar: Author Only Title Only Author and Title

Shen M, Broeckling CD, Chu EY, Zegler G, Baxter IR, Prenni JE, Hoekenga OA(2013) Leveraging non-targeted metabolite profiling via statistical genomics. PLoS One 8: e57667

Google Scholar: Author Only Title Only Author and Title

Shepherd T, Wynne Griffiths D (2006) The effects of stress on plant cuticular waxes. New Phytol 171: $469-499$ 
Google Scholar: Author Only Title Only Author and Title

Steuer R (2006) Review: On the analysis and interpretation of correlations in metabolomic data. Brief Bioinform 7: 151-158

Google Scholar: Author Only Title Only Author and Title

Sulpice R, Pyl E-T, Ishihara H, Trenkamp S, Steinfath M, Witucka-Wall H, Gibon Y, Usadel B, Poree F, Piques MC, et al (2009) Starch as a major integrator in the regulation of plant growth. Proc Natl Acad Sci 106: 10348-10353

Google Scholar: Author Only Title Only Author and Title

Swanson-Wagner RA, DeCook R, Jia Y, Bancroft T, Ji T, Zhao X, Nettleton D, Schnable PS (2009) Paternal dominance of trans-eQTL influences gene expression patterns in maize hybrids. Science 326: 1118-1120

Google Scholar: Author Only Title Only Author and Title

Tarpley L, Duran AL, Kebrom TH, Sumner LW(2005) Biomarker metabolites capturing the metabolite variance present in a rice plant developmental period. BMC Plant Biol 5: 8

Google Scholar: Author Only Title Only Author and Title

Toubiana D, Xue W, Zhang N, Kremling K, Gur A, Pilosof S, Gibon Y, Stitt M, Buckler ES, Fernie AR, et al (2016) Correlation-based network analysis of metabolite and enzyme profiles reveals a role of citrate biosynthesis in modulating $\mathrm{N}$ and $\mathrm{C}$ metabolism in Zea mays. Front Plant Sci. doi: 10.3389/fpls.2016.01022

Google Scholar: Author Only Title Only Author and Title

Trivedi P, Nguyen N, Hykkerud AL, Häggman H, Martinussen I, Jaakola L, Karppinen K (2019) Developmental and environmental regulation of cuticular wax biosynthesis in fleshy fruits. Front Plant Sci. doi: 10.3389/fpls.2019.00431

Google Scholar: Author Only Title Only Author and Title

Wang DR, Guadagno CR, Mao X, Mackay DS, Pleban JR, Baker RL, Weinig C, Jannink J-L, Ewers BE (2019) Aframework for genomicsinformed ecophysiological modeling in plants. J Exp Bot 70: 2561-2574

Google Scholar: Author Only Title Only Author and Title

Warth B, Parich A, Bueschl C, Schoefbeck D, Neumann NKN, Kluger B, Schuster K, Krska R, Adam G, Lemmens M, et al (2015) GC-MS based targeted metabolic profiling identifies changes in the wheat metabolome following deoxynivalenol treatment. Metabolomics 11: 722-738

Google Scholar: Author Only Title Only Author and Title

Watanabe M, Balazadeh S, Tohge T, Erban A, Giavalisco P, Kopka J, Mueller-Roeber B, Fernie AR, Hoefgen R (2013) Comprehensive dissection of spatiotemporal metabolic shifts in primary, secondary, and lipid metabolism during developmental senescence in Arabidopsis. Plant Physiol 162: 1290-1310

Google Scholar: Author Only Title Only Author and Title

Wen M, Jetter R (2009) Composition of secondary alcohols, ketones, alkanediols, and ketols in Arabidopsis thaliana cuticular waxes. J Exp Bot 60: 1811-1821

Google Scholar: Author Only Title Only Author and Title

Worley B, Powers R (2012) Multivariate analysis in metabolomics. Curr Metabolomics 1: 92-107

Google Scholar: Author Only Title Only Author and Title

Xue D, Zhang X, Lu X, Chen G, Chen Z-H (2017) Molecular and evolutionary mechanisms of cuticular wax for plant drought tolerance. Front Plant Sci. doi: 10.3389/fpls.2017.00621

Google Scholar: Author Only Title Only Author and Title

Yandeau-Nelson M (2015) Advances in metabolomic applications in plant genetics and breeding. CAB Rev Perspect Agric Vet Sci Nutr Nat Resour. doi: 10.1079/PAVSNNR201510040

Google Scholar: Author Only Title Only Author and Title

Yang G, Wiseman BR, Espelie KE (1992) Cuticular lipids from silks of seven corn genotypes and their effect on development of corn earworm larvae [Helicoverpa zea (Boddie)]. J Agric Food Chem 40: 1058-1061

Google Scholar: Author Only Title Only Author and Title

Yeats TH, Rose JKC (2013) The Formation and Function of Plant Cuticles. Plant Physiol 163: 5-20

Google Scholar: Author Only Title Only Author and Title

Zhou S, Kremling KA, Bandillo N, Richter A, Zhang YK, Ahern KR, Artyukhin AB, Hui JX, Younkin GC, Schroeder FC, et al (2019) Metabolome-scale genome-wide association studies reveal chemical diversity and genetic control of maize specialized metabolites.

Plant Cell 31: 937-955

Google Scholar: Author Only Title Only Author and Title 